Linköping Studies in Science and Technology

Dissertation No. 1821

\title{
Surface Integrity and Fatigue Performance of Nickel-based Superalloys
}

\author{
Zhe Chen
}

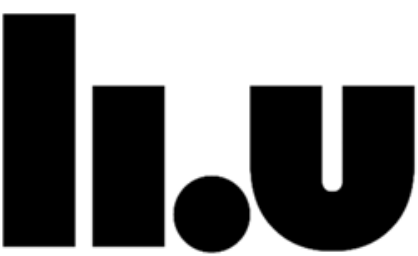

LINKÖPING UNIVERSITY

\author{
Division of Engineering Materials \\ Department of Management and Engineering \\ Linköping University, SE-581 83, Linköping, Sweden \\ http://www.liu.se
}

Linköping, February 2017 
Opponent: Professor Manuel François, Université de Technologie de Troyes (University of Technology of Troyes), France.

Date: February 17, 2017

Room: ACAS, Hus A, Campus Valla, Linköping University

Cover: Designed by Zhe Chen and Tianwei Xu.

Main body-gas turbine illustration. Courtesy of David Gustafsson/Siemens.

Background-flame dragon. Free download. Courtesy of the website, https://www.desktopnexus.com.

Printed by:

LiU-Tryck, Linköping, Sweden, 2017

ISBN: 978-91-7685-600-0

ISSN 0345-7524

Distributed by:

Division of Engineering Materials

Department of Management and Engineering

Linköping University

SE-581 83, Linköping, Sweden

\section{(C) 2017 Zhe Chen}

No part of this publication can be reproduced, stored in a retrieval system, or transmitted, in any form or by any means, without prior permission of the author. 


\section{Abstract}

Gas turbines are widely used in e.g., power generation, and aero- industries. Due to global warming, the demand for more efficient gas turbines has increased. A way to achieve this is by increasing the operating temperature of gas turbines. Therefore, nickel-based superalloys have been developed to withstand these extreme temperatures and loads, especially in the hot sections.

Today, the way of operating land-based gas turbines is changing. Instead of running for long periods of time, the operation is becoming more flexible, with everincreasing cyclic loads and number of start and stop cycles. To handle the increased stress and cycles, component resistance to fatigue failure needs to be improved.

Surface integrity is critical to fatigue performance, since fatigue cracks are normally initiated at surfaces. Nickel-based superalloys are difficult-to-machine materials, primarily due to their high strength, high tendency for work-hardening, and low thermal conductivity. The machining process changes the surface integrity of the alloys which can result in worse fatigue resistance.

The work presented in this Ph.D. thesis was conducted in collaboration with Siemens Industrial Turbomachinery AB in Finspång, Sweden. Surface integrity changes which are induced during machining and their effects on fatigue performance have been studied on alloy Inconel 718. Inconel 718 is a widely-used nickel-based superalloy for high temperature applications in modern gas turbines.

Broaching, milling, and wire electrical discharge machining, related to component manufacturing in turbo machinery industries, were included in this study. Surface irregularity and defects induced by machining provide preferential sites for fatigue crack initiation which influence the fatigue performance of the alloy. If compressive residual stresses are induced during machining, they benefit the fatigue life by retarding fatigue crack initiation away from surface regions. Shot peening was performed on machined Inconel 718, by which high compressive residual stresses are deliberately induced. It results in increased fatigue performance. The high 
temperatures in gas turbines generally deteriorate the surface integrity. For instance, recrystallization often occurs in the highly plastically-deformed surface layer. Microstructural degradation, in a form of $\alpha$-Cr precipitates, have also been observed in the deformed surface and sub-surface microstructure when subjected to thermal exposure. Oxidation at elevated temperatures was found to degrade the surface integrity and thereby also the fatigue performance. Fatigue cracks are preferably initiated at oxidized surface carbides, if thermal exposure has been made prior to the test, and a reduced fatigue life is often obtained. It is even worse when high temperatures relax the beneficial compressive residual stresses induced by shotpeening and thereby lowering the fatigue resistance. This increases the interest for research regarding how to optimize the shot peening process in order to enhance the thermal stability of the surface compression.

Machinability of a newly developed nickel-based superalloy, $\mathrm{AD} 730^{\mathrm{TM}}$, and the surface integrity induced during turning have also been studied in this thesis project. $\mathrm{AD} 730^{\mathrm{TM}}$ is a candidate for turbine disc applications with an operating temperature above $650{ }^{\circ} \mathrm{C}$. At such high temperatures, Inconel 718 is no longer stable and its mechanical properties start to degrade.

To summarize, the results from this thesis work show the importance of understanding surface integrity effects for fatigue applications, especially in harsh environments. More importantly, the knowledge gained through this work could be used for surface enhancement of turbine components which are subjected to a high risk of fatigue failure. It is believed that this thesis work will contribute to more efficient and flexible power generation by gas turbines. 


\section{Populärvetenskaplig sammanfattning}

\section{Ytintegritet och utmattningsegenskaper av nickelbaserade superlegeringar}

Gasturbiner används i industrier som t.ex. elkraft och flyg. På grund av växthuseffekten vill man öka effektiviteten hos gasturbiner. Ett sätt att göra det på är att öka operations temperaturen. Därför har nickelbaserade superlegeringar utvecklats för att klara av höga temperaturer och laster, speciellt i högtemperatur sektionerna i gasturbiner.

Användandet av gasturbiner ändras ständigt. Istället för att vara i gång konstant över längre tider så vill man köra dem mer flexibelt. Helt enkelt fler start och stopp cykler. Den ökande flexibiliteten och start och stopp cykler har lett till att man behöver få en ökad förståelse av utmattning av utsatta komponenter.

Ytintegriteten är kritisk när det gäller utmattning och i normala fall initierar utmattningssprickor på ytor. Nickelbaserade superlegeringar är svåra att maskinbeta p.g.a. deformationshårdnande och låg termisk överföring. Maskinbearbetning ändrar ytintegriteten och kan leda till sämre utmattningsegenskaper.

Arbetet i den här doktorsavhandlingen utfördes i samarbete med Siemens Industrial Turbomachinery AB i Finspång, Sverige. Ytintegritets problem som kan uppstå under maskinbearbetning av Inconel 718 i produktion och hur dem påverkar utmattningsegenskaperna har studerats. Inconel 718 är en vanligt förkommande superlegering för högtemperatur applikationer i moderna gasturbiner.

Brotchning, fräsning och trådgnistning har inkluderats för att de används i turbinindustrier. Ytdefekter inducerade p.g.a. maskinbearbetning blir optimala initieringspunkter för utmattningssprickor och påverkar utmattningslivslängden av Inconel 718. Om man inducerar kompressiva restspänningar i ytan så förbättras utmattningsegenskaperna genom att man retarderar sprickiniteringen från ytan. 
Därför har även kompressiva restspänningar inducerats via kulpening. Vilket resulterade i bättre utmattningsmotsånd.

Dom höga temperaturerna i gasturbinerna försämrar oftast ytintegriteten, via t.ex. rekristallisation som vanligen förekommer i ytområdena som plasticerats i hög grad. Mikrostrukturel degradering förekommande $\mathrm{i}$ form av $\alpha$-Cr utskiljningar har observerats i både dem deformerade yt och underyt regionerna när materialet utsatts termiskt. Högtemperatur oxidation visade sig också vara skadligt för ytintegriteten. Utmattningsprickorna initierade vanligtvis från oxiderade karbider på ytan. Värmebehandling innan provning visade sig också vara sämre för utmattningslivslängden. Det vart ännu sämre resultat när den höga temperaturen relaxerade dem kompressiva restspänningarna inducerade via kulpening. Det här ökar intresset för forskning kring optimering av kulpeningsprocessen för att öka den termiska stabiliteten av dem kompressiva restspänningarna i ytan.

Svarvning av den nyutvecklade superlegeringen $\mathrm{AD} 730^{\mathrm{TM}}$ och den där av inducerade ytintegriteten har också studerats. $\mathrm{AD} 730^{\mathrm{TM}}$ är en turbinskivsmaterialkandidat som ska kunna användas vid temperaturer över $650^{\circ} \mathrm{C}$ vid vilken Inconel 718 inte längre är stabilt och börjar förlora sina mekaniska egenskaper.

Sammanfattningsvis visar resultaten i den här doktorsavhandlingen hur viktigt det är att förstå hur ytintegriteten påverkar utmattningsegenskaperna i olika applikationer, speciellt i krävande miljöer. Kunskapen erhållen från studierna skulle kunna användas till att förbättra ytegenskaperna av komponenter som utsätts för utmattning. Slutligen kan den här doktorsavhandlingen bidra till en mer effektiv och flexibel kraftproduktion av gasturbiner. 


\section{Acknowledgements}

My first contact with nickel-based superalloys was in a presentation when I was a Master student in China. This presentation led me to the world of gas turbine and caught my interest with those "super" alloys. Nothing could be better than that the speaker later became the main supervisor of my doctoral study. During the past four and half years, there are many people for whom I would like to express my gratitude. First and foremost, I would like to thank the speaker, my main supervisor, Ru Lin Peng. Thank you for bringing me to this fantastic "super" world, for giving me the opportunity to come to Sweden to start my academic journey, and also for your trust, support, and encouragement since I started this Ph.D. project.

A great thanks also goes to my co-supervisors, Johan Moverare and Sten Johansson, for the profitable and inspiring discussions that we had during the time when I got stuck or confused in the project, and a further thanks to them for always taking the time with my articles and giving constructive suggestions with the writing. My apology goes to Johan since I guess that I have never pronounced his family name properly because of my difficulty in the pronunciation of the Swedish " $R$ ".

The research project that led to this thesis has been carried out with great support from Siemens Industrial Turbomachinery AB in Finspång, Sweden, and therefore it is greatly acknowledged. A special thanks is addressed to Pajazit Avdovic, Fredrik Karlsson, David Gustafsson, Per Almroth, and Frans Palmert for their valuable discussions, sharing of ideas, and positive feedback during many project meetings. Although it is not a long distance from Finspång to Linköping, however, it is still not that charming when driving in the cold and dark winter.

The Strategic Faculty Grant AFM (SFO-MAT-LiU\#2009-00971) at Linköping University and ÅForsk Foundation Grant 15-334 are also acknowledged for their financial support in some of the investigations in the project.

Many collaborations have been created during this project work. I would like to take this opportunity to express my gratitude to our partners, Jinming Zhou at Lund 
University, Magnus Hörnqvist Colliander at Chalmers University of Technology, and Olle Widman from Ytstruktur Arboga AB in Arboga, Sweden for the time and energy that they have spent. I am looking forward to continue our collaboration in the future.

A collective thanks goes to the whole Engineering Materials group for creating such great and comfortable working environment. Before I came to Sweden, I was aware of the cold and dark Swedish winter. However, I have never felt it when I am sitting in the corridor. A special thanks was sent to Ingmari Hallkvist, our administrator, for keeping the group in perfect order and also for the invisible administrative work behind every individuals. Annethe Billenius and Patrik Härnman are also greatly acknowledged for their excellent lab management and the technical support on the lab work. I would like to further express my appreciation to Viktor Norman for his contribution to the ambitious and high-efficient atmosphere at the office.

My thanks are also addressed to all the great Ph.D. students that I got to know in IEI, IFM, and Agora Materiae during these years. We have together had nice seminars, dinners, summer conferences, and study visits. Thank you Per-Olof Holtz for running the Agora Materiae group. I also would like to give my gratitude to Yifeng Zhu, for his help in drawing the schematic illustrations of broaching and turbine disc.

There are so many wonderful memories during the four and half years of staying in Sweden. I would like to express my deep appreciation to my friends for without my life will not be such colorful. Jonas and Robert, thank you for teaching me how to brew super strong and sweet beers. Mattias, thanks you for taking me to watch my first dog racing. Viktor, thank you for supervising the progress of my Swedish and creating the Swedish-Chinese learning board. Emma, Johan, and my friends at Campushallen, thanks for the great basketball time that we had together. Zebo, Ou, Xinhai, and the badminton group, thanks for those wonderful games on every Saturday morning. Linn, Ya, and my Chinese friends sitting in the Hus A, thank you for making me have my lunch on time every day. I feel extremely lucky to have the opportunity to meet my happy group, Kang, Zhenyuan, Shuoguo, Daqing, Lihua, Yixuan, Lujie, Guoming, Yuan, Jun, Fei, Shengnan, Jiawen, Lu, Libby, and many others. Thank you all for the parties, movie nights, games, and after-dinner crazy talks, especially during the less sunny days.

At last, I want to give my deepest thanks to my parents and girlfriend. Dear mom and dad, thank you for your endless love, patience, and support, for always believing in me, and for always being there by my side. My dear love, Tianwei, thanks for coming into my life and for your love and accompany. You are the best thing that happened to me, you are the best thing that is still happening to me, and you are going to be the best thing to happen to me. 
Shante you wery much

Sacti sai myleet

Ghe Chen Linköping, January 2017 



\section{List of Papers}

In this Ph.D. thesis, the following papers are included:

I. Z. Chen, R. Lin Peng, J. Moverare, P. Avdovic, J.M. Zhou, S. Johansson, Surface integrity and structural stability of broached Inconel 718 at high temperatures. Metall. Mater. Trans. A, 47(2016), 3664-3676.

II. Z. Chen, J.J. Moverare, R. Lin Peng, S. Johansson, D. Gustafsson, On the conjoint influence of broaching and heat treatment on bending fatigue behavior of Inconel 718. Mater. Sci. Eng. A, 671(2016), 158-169.

III. Z. Chen, M.H. Colliander, G. Sundell, R. Lin Peng, J.M. Zhou, S. Johansson, J. Moverare, Nano-scale characterization of white layer in broached Inconel 718. Mater. Sci. Eng. A, 684(2016), 373-384.

IV. Z. Chen, R. Lin Peng, J. Moverare, O. Widman, D. Gustafsson, P. Almroth, S. Johansson, Residual stress and thermal relaxation of shot-peened Inconel 718 nickelbased superalloy. In manuscript.

V. Z. Chen, R. Lin Peng, J. Moverare, O. Widman, D. Gustafsson, S. Johansson, Effect of cooling and shot peening on residual stresses and fatigue performance of milled Inconel 718. In: Residual Stresses 2016: ICRS 10 (T.M. Holden, O. Muránsky, and L. Edwards, Eds.), Materials Research Forum LLC, Materials Research Proceedings, 2(2016), 13-18.

VI. Z. Chen, J. Moverare, R. Lin Peng, O. Widman, D. Gustafsson, P. Almroth, $\mathrm{S}$. Johansson, Effect of thermal exposure on fatigue performance of shot-peened Inconel 718. In manuscript. 
VII. Z. Chen, J. Moverare, R. Lin Peng, S. Johansson, Surface integrity and fatigue performance of Inconel 718 in wire electrical discharge machining. Procedia CIRP, 45(2016), 307-310.

VIII. Z. Chen, R. Lin Peng, J.M. Zhou, V. Bushlya, R.M. Saoubi, S. Johansson, J. Moverare, Effect of cutting conditions on machinability of $A D 730^{T M}$ during high speed turning with PCBN tools. In manuscript.

Papers not included in this thesis:

IX. R. Eriksson, Z. Chen, K.P. Jonnalagadda, Bending fatigue of thermal barrier coatings. Submitted to ASME Turbo Expo 2017.

X. Z. Chen, R. Lin Peng, P. Avdovic, J.M. Zhou, J. Moverare, F. Karlsson, S. Johansson, Effect of thermal exposure on microstructure and nano-hardness of broached Inconel 718. In: EUROSUPERALLOYS 2014-2 ${ }^{\text {nd }}$ European Symposium on Superalloys and Their Applications (J.Y. Guédou and J. Choné, Eds.), EDP Sciences, MATEC Web of Conferences, 14(2014), 08002-p.1-08002-p.6.

XI. Z. Chen, R. Lin Peng, P. Avdovic, J. Moverare, F. Karlsson, J.M. Zhou, S. Johansson, Analysis of thermal effect on residual stresses of broached Inconel 718. Advanced Materials Research, 966(2014), 574-579.

XII. Z. Chen, J. Moverare, R. Lin Peng, S. Johansson, Damage analysis of a retired gas turbine disc. In: Proceedings of Energy Materials 2014, TMS, 2014.

XIII. J.M. Zhou, V. Bushlya, R. Lin Peng, Z. Chen, S. Johansson, J.E. Ståhl, Analysis of subsurface microstructure and residual stresses in machined Inconel 718 with PCBN and $\mathrm{Al}_{2} \mathrm{O}_{3}-\mathrm{SiC}_{w}$ tools. Procedia CIRP, 13(2014), 150-155.

XIV. R. Lin Peng, J. Moverare, P. Avdovic, A. Billenius, Z. Chen, Influence of vibration and heat treatment on residual stress of a machined $12 \%$ Cr-steel. Advanced Materials Research, 966(2014), 609-614.

XV. Z. Chen, R. Lin Peng, J.M. Zhou, J. Moverare, V. Bushlya, S. Johansson, ECCI and EBSD study of subsurface damages in high speed turning of Inconel 718 under different tools and macbining parameters. Presented at ICF13, Beijing (China), 2013. 


\section{Contents}

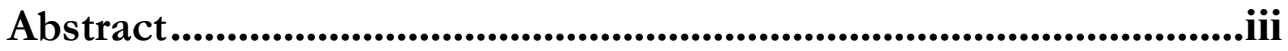

Populärvetenskaplig sammanfattning.......................................................v

Acknowledgements......................................................................................vii

List of Papers..............................................................................................

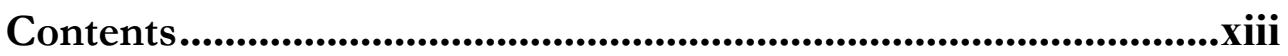

Part I Background \& Methodology.........................................1

1. Introduction.....................................................................................

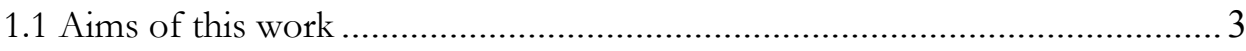

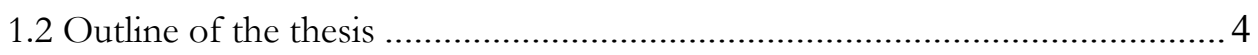

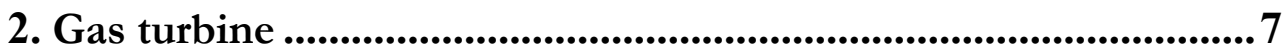

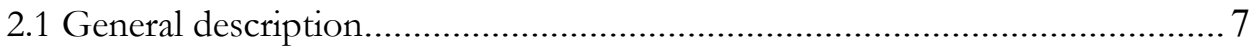

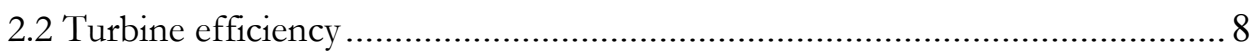

2.3 Fatigue failure in gas turbines.................................................................. 9

3. Nickel-based superalloys..................................................................11

3.1 Composition and microstructure ……............................................... 12

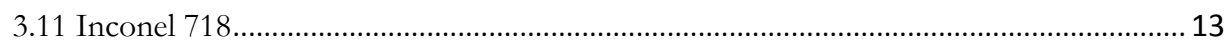

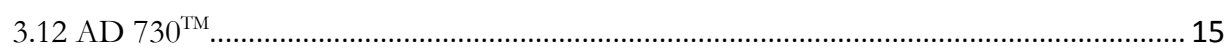

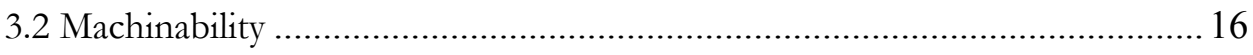

4. Machining \& Shot peening ........................................................19

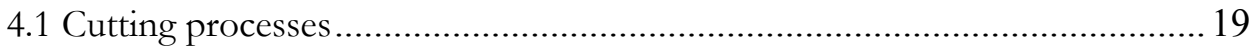




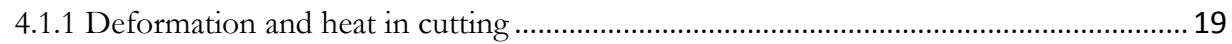

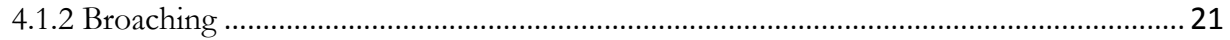

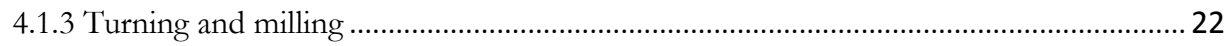

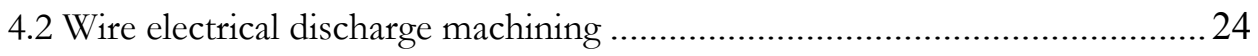

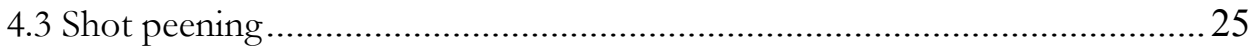

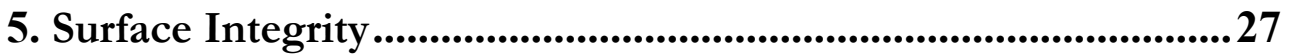

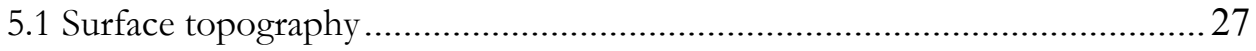

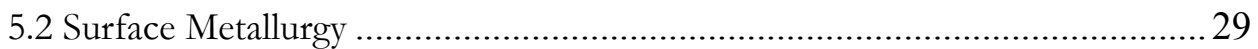

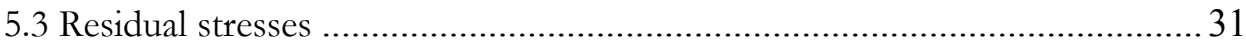

5.4 Effect of thermal exposure .......................................................... 33

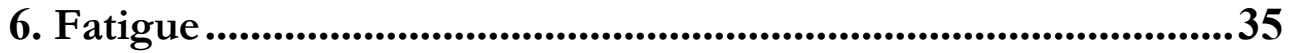

6.1 Introduction .............................................................................. 35

6.2 Crack initiation ........................................................................ 36

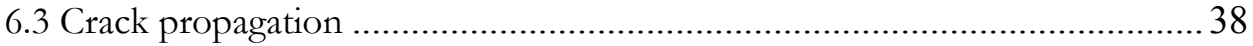

7. Experimental methods ..............................................................44

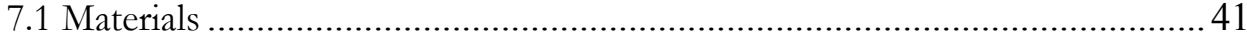

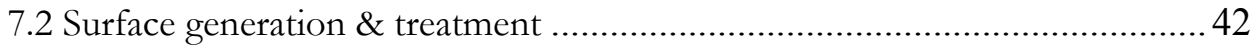

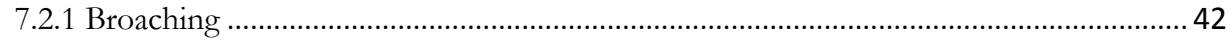

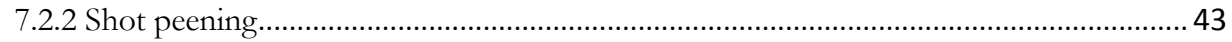

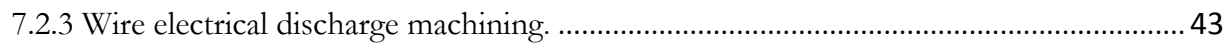

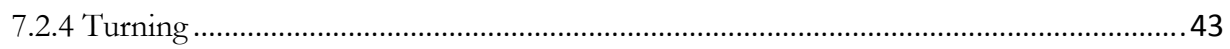

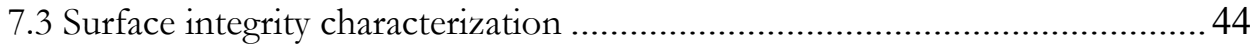

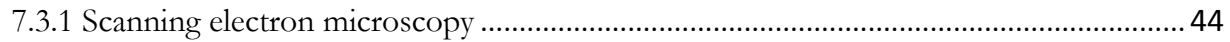

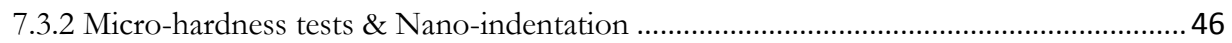

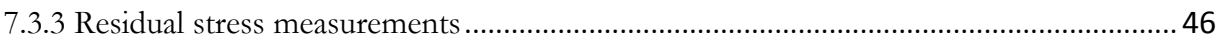

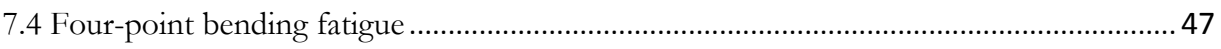

8. Review of papers included ............................................................449

9. Conclusions ................................................................................55

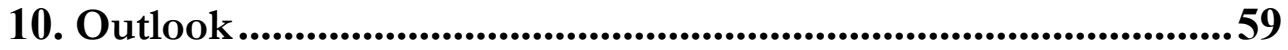

Bibliography ...................................................................................................61 
Paper I: Surface integrity and structural stability of broached Inconel 718 at high temperatures

Paper II: On the conjoint influence of broaching and heat treatment on bending fatigue behavior of Inconel 718

Paper III: Nano-scale characterization of white layer in broached Inconel 718

Paper IV: Residual stress and thermal relaxation of shot-peened Inconel 718 nickelbased superalloy

Paper V: Effect of cooling and shot peening on residual stresses and fatigue performance of milled Inconel 718

Paper VI: Effect of thermal exposure on fatigue performance of shot-peened Inconel 718

Paper VII: Surface integrity and fatigue performance of Inconel 718 in wire electrical discharge machining

Paper VIII: Effect of cutting conditions on machinability of AD $730^{\mathrm{TM}}$ during high speed turning with PCBN tools 



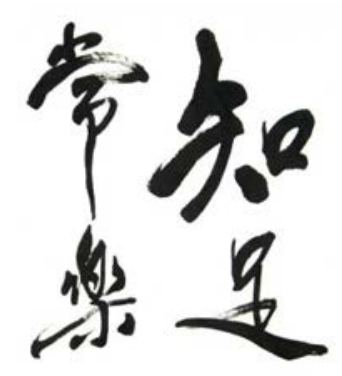

A contented mind is the greatest blessing a man can enjoy in this world.

老子 (春秋战国思想家)

Lao Tse (Chinese Philosopher in the Spring and Autumn Period) 



\section{Part I}

Background \& Methodology 



\section{Introduction}

Due to both environmental and economic concerns, demand for more efficient gas turbines has been dramatically increased in power generation and aviation industries. Meanwhile, a more flexible way of energy generation by means of wind power, solar power and nuclear power is being created. Land-based gas turbines nowadays are used in different ways to how it was used previously; instead of running over long periods of time, the operation is more flexible with an increased number of start and stop cycles.

One approach to increase turbine efficiency is by increasing operating temperatures [1]. Nickel-based superalloys have excellent mechanical properties and good oxidation resistance at elevated temperatures. They are used in hot sections e.g., combustor nozzles, turbine discs, and blades. Probability of fatigue failure increases in gas turbines with increasing stresses and number of cycles. Therefore, fatigue resistance of nickel-based superalloys need to be improved. Relevant research, particularly those closely connected to turbine industrial applications, is crucial.

\subsection{Aims of this work}

The work presented in this Ph.D. thesis has been carried out within the project Surface Integrity and Fatigue Performance of Nickel-based Superalloys. It has long been recognized that fatigue cracks normally originate at a surface [2]. This is due to the fact that surface layers experience the highest load and are exposed to environmental effects. The surface quality/integrity, therefore, plays an important role on component resistance to cyclic loads. The overall aims of this project are to: 
i. Investigate a) surface integrity changes that could be created during machining of nickel-based superalloys, and b) surface enhancement by post-machining surface treatments;

ii. Study surface integrity changes when subjected to thermal exposure at elevated temperatures for high temperature applications;

iii. Increase knowledge with regard to the fatigue behavior and performance as influenced by surface integrity.

This project involves strong collaboration between academia and industries, e.g., Linköping University, Chalmers University of Technology, and Lund University in Sweden, Siemens Industrial Turbomachinery $\mathrm{AB}$ in Finspång, Sweden, and Ytstruktur Arboga AB in Arboga, Sweden. Broaching, turning, milling, and wire electrical discharge machining have been included, since they are commonly used in turbo machinery industries. Shot peening is also of great interest since it is a method of surface enhancement which can improve fatigue resistance of components [3]. Two nickel-based superalloys, Inconel 718 (in the form of forged bulk) and AD $730^{\mathrm{TM}}$ (bar), were investigated. The major part of the project work has been dedicated to the alloy Inconel 718. Inconel 718 is one of the most widely used nickel-based superalloys for high temperature applications in gas turbines, for instance, it is frequently used as a disc material in the turbine section. $\mathrm{AD} 730^{\mathrm{TM}}$ is recently been developed and it has a good combination of manufacturing cost and mechanical property with a temperature capability up to $750{ }^{\circ} \mathrm{C}$ [4]. AD $730^{\mathrm{TM}}$ is an attractive candidate for turbine disc applications which operate above $650^{\circ} \mathrm{C}$. At such high temperatures, Inconel 718 is no longer stable for use as its mechanical properties start to degrade.

With the extensive investigations carried out in this thesis work, we aim to have a better understanding of fatigue failure in gas turbine components by taking surface effects into consideration. More importantly, the knowledge gained can later be used for surface enhancement of turbine components which operate at a high risk of fatigue failure, thereby improving the durability, reliability, and flexibility for gas turbine applications.

\subsection{Outline of the thesis}

This thesis consists of a kappa, Part I, and eight articles, Part II. The kappa is an introductory text in which the different parts of the thesis are integrated. It was built upon the licentiate thesis Surface Integrity of Broached Inconel 718 and Influence of Thermal Exposure [5], which was presented in October, 2014. Since then new work has been conducted, which is presented in this Ph.D. thesis. 


\section{Part I - Background \& Methodology}

The kappa consists of ten chapters, giving an introduction to the project that underlies this Ph.D. thesis (Chapter 1), the background of research fields related to the project (Chapter 2 to 6 ), and the experimental methods that have been mainly used for the investigations (Chapter 7). Chapter 8 reviews the papers appended in Part II, and more importantly integrates the papers with the research aims. In Chapter 9, the main conclusions from this thesis work are presented and their contributions are highlighted from both academic and industrial point of view. In Chapter 10, the author describes the outlook of research interest for future investigations based on this Ph.D. thesis work.

\section{Part II - Papers Included}

In this part, eight papers correlated to the main studies that have been performed within the frame of the project are collected. In Paper I to III, surface integrity and fatigue performance of broached Inconel 718, and the influence of thermal exposure, are addressed. From Paper IV to VI, the research focus has been paid on shot peening where issues like surface integrity and fatigue performance of shot-peened Inconel 718 are investigated in comparison with that in the milled alloy. Meanwhile, thermal relaxation of the surface compression induced by shot peening at elevated temperatures, and its effect on fatigue are also addressed in details. Paper VII presents another investigation with respect to wire electrical discharge machining (WEDM) of the Inconel 718. In the last Paper VIII, the machinability of a new alloy AD $730^{\mathrm{TM}}$ is evaluated in terms of cutting forces, machining induced plastic deformation, and generation of residual stresses during high speed turning with uncoated PCBN tools at various cutting speeds and feed rates. These eight papers are not arranged in chronological order, but instead, are organized by the content associated with the process how the surface is generated, and certainly they are closely related to the project aims, as illustrated in Fig. 1. 


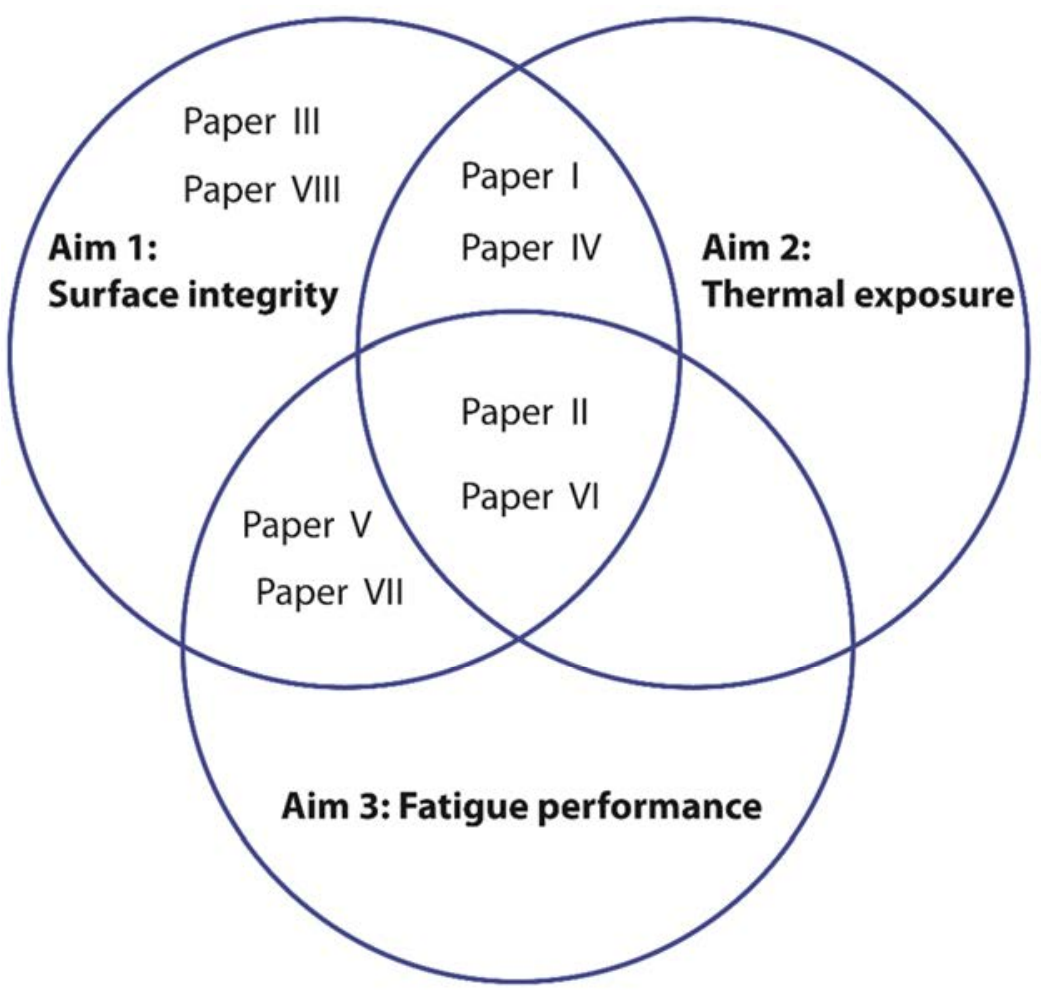

Figure 1. Connections between the project aims and each individual paper. 


\section{Gas turbine}

\subsection{General description}

A Siemens land-based gas turbine, SGT-800 for power generation is schematically illustrated in Fig. 2. Fresh atmospheric air is taken in through the air inlet, and then compressed by compressor discs and blades when it flows through the compressor. In the combustor, the compressed hot air is mixed with fuel, and ignited, generating a high-temperature flow. The high-temperature and high-pressure fluid expands through the turbine section, and mechanical energy is extracted by the turbine blades and discs which start to rotate.

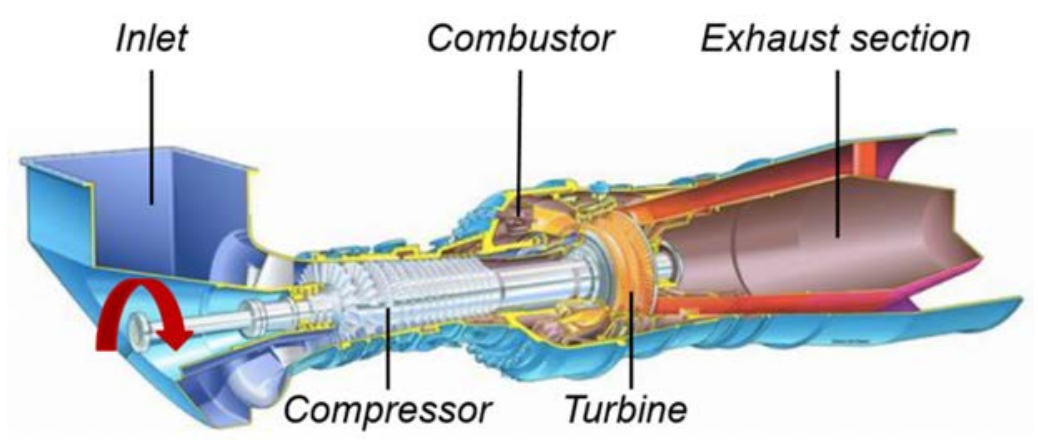

Figure 2. SGT-800 gas turbine (Courtesy of Siemens Industrial Turbomachinery AB).

The rotating turbine disc is coupled to a shaft which transfers the mechanical energy to drive external machinery such as electric generator, cruise ships, or oil and gas pipeline pumps, etc. Not all the mechanical energy generated from the turbine stage is converted and output for power generation since the shaft also needs to drive the 
compressor to spin. The remaining heat from the exhaust gas can be used in combined cycles to produce steam for steam turbines or heat water for daily use. The function of an aero engine is similar to that of the land-based gas turbine. However, the burning gases expand and blast out through the nozzle, at the back of the engine, generating thrust for aircrafts.

\subsection{Turbine efficiency}

Modern gas turbine engines work following the principle based on the Joule-Brayton cycle as illustrated in Fig. 3. It consists of one stage of isentropic compression when ambient air is compressed in the compressor (between points a and b) and an isentropic expansion stage, causing the heated air and combustion products to expand through the turbine section (between points $\mathrm{c}$ and d). In the combustor, fuel is added at constant pressure, i.e. an isobaric process (between points b and c), therefore, leading to an increase in temperature and volume expansion. The efficiency of an ideal Joule-Brayton cycle can be described as follows:

$$
\eta=1-\left(T_{2} / T_{1}\right)^{-1}=1-\left(P_{2} / P_{1}\right)^{(1-\gamma) / \gamma}
$$

Where $\eta$ is the thermal efficiency, $T_{2} / T_{1}$ and $P_{2} / P_{1}$ are respectively the temperature ratio and pressure ratio across the compressor, and $\gamma$ is the adiabatic index respectively. Increasing the compression ratio is the most direct way to increase the overall power output of a gas turbine, however, simultaneously it leads to a temperature increment of the working fluid passing through the compressor, combustor, and turbine sections. The limit strongly depends on the high-temperature durability of the materials used in these sections.

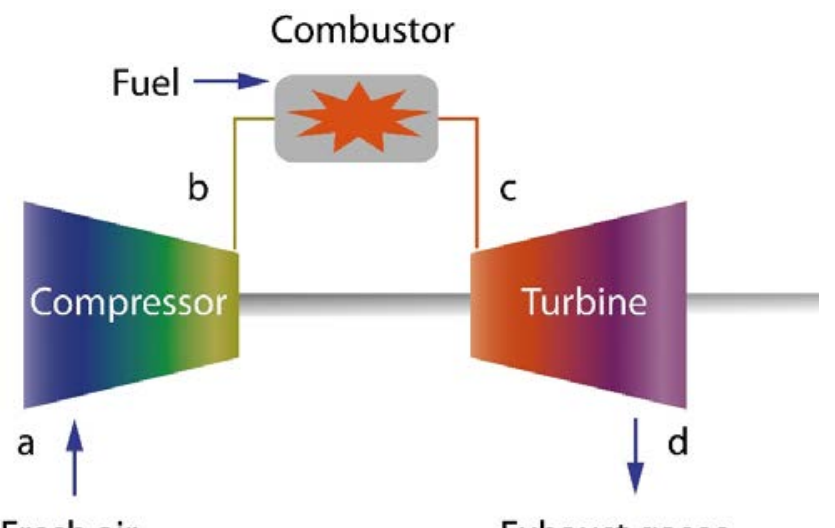

Fresh air

Exhaust gases

Figure 3. Schematic illustration of the open circuit gas turbine system. 


\subsection{Fatigue failure in gas turbines}

Fatigue, including both high (HCF) and low cycle fatigue (LCF), is one of the largest cause of component failure in modern gas turbine engines [6-9]. There are several different origins, leading to HCF damages in a gas turbine, which can be generally classified as follows [7]:

- Aerodynamic excitations, primarily affecting turbine blades, vanes, and bladedisc joint parts, caused by engine flow pressure perturbations;

- Mechanical vibration due to rotor unbalance, mostly taking place on rotating apparatus;

- Airfoil flutter caused by aeromechanical instability, affecting turbine blades;

- Acoustic fatigue, which is a failure mechanism commonly seen on sheet metal components in the combustor and nozzle.

With such a diversity of HCF drivers, many engine components are susceptible to HCF damages. LCF is a different matter and primarily related to the much larger stress cycles imposed either by starting and stopping or by over-speeding in operation [6]. The source of these cyclic stresses is fairly obvious. For instance, when stopped running, the blade-disc joint part is lightly loaded mainly due to self-weight, and it is cold at room temperature, while the same part will be subjected to large loadings from centrifugal forces imposed by the rotational speed, and also to a much higher temperature during the operation. The change between these two states takes place rapidly on engine start, which induces high levels of thermal stress, and the thermal stress is reduced to a steady value when the engine is running and then reappeared, in reverse, during cooling. Plenty of critical components in a gas turbine, such as turbine discs, are life limited by the number of start and stop cycles to which they are subjected in service, rather than by the total hours of service. 



\section{3}

\section{Nickel-based superalloys}

The emergence of the nickel-based superalloys can be traced back to the development of the modern gas turbines where high-temperature resistant materials are greatly demanded to enable a higher power output efficiency by operating the turbine at higher temperatures. These alloys have been designed to withstand service temperatures beyond $540{ }^{\circ} \mathrm{C}$ up to $1000{ }^{\circ} \mathrm{C}$, in particular when resistance to creep and fatigue is required. The mechanical properties of ordinary steels and titanium alloys degrade remarkably in this temperature range, as illustrated in Fig. 4. The good resistance to oxidative and corrosive environments also make nickel-based superalloys to be an excellent choice of material for high temperature applications.

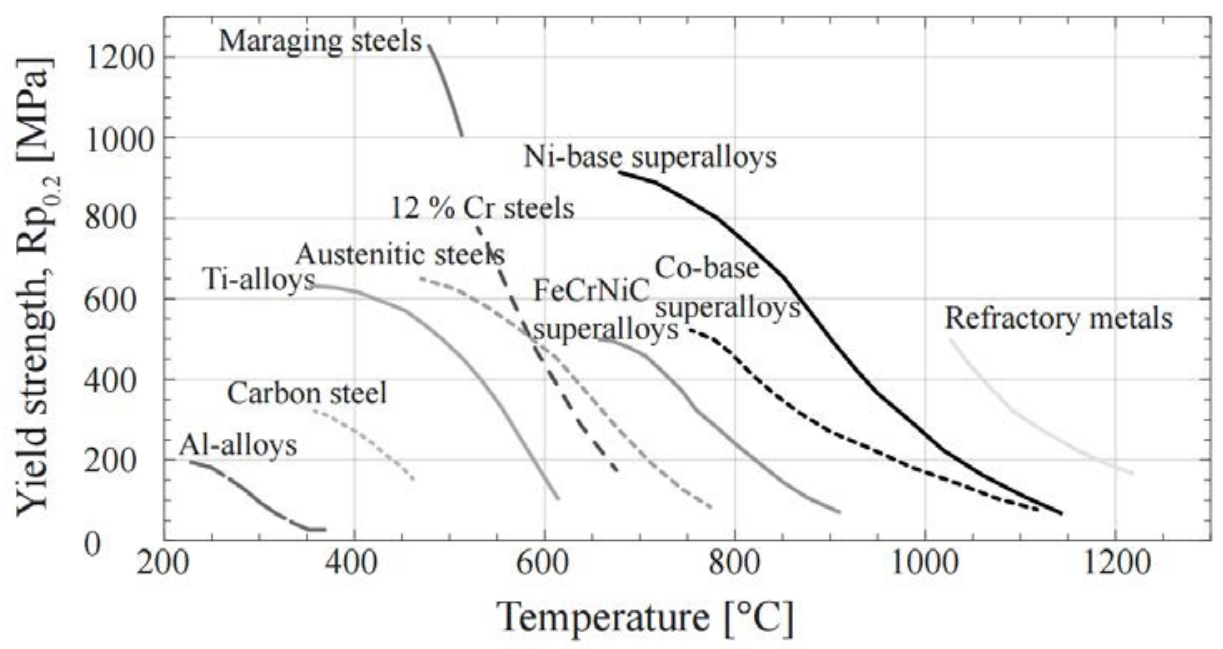

Figure 4. Maximum service temperature for different alloy groups [10]. 


\subsection{Composition and microstructure}

The great high temperature performance of the nickel-based superalloys is strongly related to the compositions of the alloys and the phases promoted by the presence of multiple alloying elements [1]. Nickel is the fifth richest element on earth. The melting temperature of the nickel is not particularly high and in fact is lower $\left(1455^{\circ} \mathrm{C}\right)$ than that of either iron or titanium. However, it has a stable face-centered cubic (FCC) crystal structure from the ambient temperature to its melting point, and as a result phase transformations are to a large extent being restricted. There are mostly over ten different alloying elements in the Ni matrix, often donated as $\gamma$; compositions for some common nickel-based superalloys are listed in Table 1. The alloys are strengthened by solid solution and precipitation. For instance, oxidation, corrosion, and sulphidation are primarily suppressed by $\mathrm{Cr}$ and $\mathrm{Co}$. Additions of $\mathrm{Al}, \mathrm{Ti}$, and $\mathrm{Ta}$ could dramatically improve the flow stress and ultimate tensile strength due to the formation of a coherent strengthening phase, $\gamma^{\prime}-\mathrm{Ni}_{3}(\mathrm{Al}, \mathrm{Ti}, \mathrm{Ta})$, which exhibits the $\mathrm{L}_{2}$ crystal structure. In many nickel-iron alloys, like Inconel $718, \mathrm{Nb}$ is added to support the precipitation of another coherent strengthening phase, $\gamma^{\prime \prime}-\mathrm{Ni}_{3} \mathrm{Nb}$ with the $\mathrm{D} 0_{22}$ structure. However, the alloys which are primarily strengthened by the $\gamma^{\prime \prime}$ precipitates are susceptible to the formation of an orthorhombic phase, $\delta$, with the same composition as the $\gamma^{\prime \prime}$, in the overaged conditions. Since the $\delta$ phase is incoherent with the $\gamma$ matrix, it does not contribute to strength even when present in considerable quantities.

Table 1. Chemical composition in $\mathrm{w} t \%$ of some common nickel-based superalloys [1].

\begin{tabular}{lcccccccccccc}
\hline \multicolumn{1}{c}{ Alloy } & $\mathrm{Ni}$ & $\mathrm{Cr}$ & $\mathrm{Co}$ & $\mathrm{Mo}$ & $\mathrm{W}$ & $\mathrm{Nb}$ & $\mathrm{Al}$ & $\mathrm{Ti}$ & $\mathrm{Fe}$ & $\mathrm{C}$ & $\mathrm{B}$ & $\mathrm{Zr}$ \\
\hline Hastelloy X & Bal. & 22.0 & 1.5 & 9.0 & 0.6 & - & 0.25 & - & 18.5 & 0.1 & - & - \\
Haynes 230 & Bal. & 22.0 & - & 2.0 & 14.0 & - & 0.3 & - & - & 0.1 & - & - \\
Haynes 282 & Bal. & 19.6 & 10.3 & 8.7 & 0.01 & 0.1 & 1.5 & 2.2 & 0.5 & 0.06 & 0.005 & - \\
Inconel 706 & Bal. & 16.0 & - & - & - & 2.9 & 0.2 & 1.8 & 40.0 & 0.03 & - & - \\
Inconel 718 & Bal. & 19.0 & - & 3.0 & - & 5.1 & 0.5 & 0.9 & 18.5 & 0.04 & - & - \\
Udimet 720 & Bal. & 17.9 & 14.7 & 3.0 & 1.25 & - & 2.5 & 5.0 & - & 0.03 & 0.033 & 0.03 \\
Waspaloy & Bal. & 19.5 & 13.5 & 4.3 & - & - & 1.3 & 3.0 & - & 0.08 & 0.006 & - \\
\hline
\end{tabular}

In addition to the elements mentioned above, Mo, Re and W, together with grain boundary strengthening elements $\mathrm{C}$ and $\mathrm{B}$, are usually added which confers better time-dependent creep performance. However, excessive additions of $\mathrm{Cr}, \mathrm{Mo}, \mathrm{W}$, and Re could promote the precipitation of intermetallic phases, such as $\alpha$-Cr [11] and various topologically close packed (TCP) phases $(\sigma, \mu$, Laves, etc.) [12], all of which can cause a decrease in rupture strength and ductility of the alloys. Carbides and borides are formed in the microstructure when carbon and boron are present. Some of the types that are commonly seen in nickel-based superalloys include $\mathrm{MC}, \mathrm{M}_{6} \mathrm{C}$, $\mathrm{M}_{23} \mathrm{C}_{6}$, and $\mathrm{M}_{3} \mathrm{~B}$, where $\mathrm{M}$ stands for strong carbide/boride formers such as $\mathrm{Cr}$, Mo, 
Ti, Ta or Hf. The MC carbides normally precipitate at high temperatures from the liquid phase, while carbides such as $\mathrm{M}_{23} \mathrm{C}_{6}$ is formed at lower temperatures, around $750{ }^{\circ} \mathrm{C}$, during extended periods of time, and their formation occurs through the decomposition of the MC carbides, usually at grain boundaries. It has been widely accepted that high-temperature creep properties are enhanced if carbides and borides are present at grain boundaries. They have beneficial effects on rupture strength via the retardation of grain boundary sliding [13].

The chemical complexity provides great possibilities for the design of new alloys with better high-temperature mechanical properties. Besides, through the process of directional solidification and the use of a 'grain selector', it has become possible to cast the alloys in single crystal form where the grain boundaries, as a source of weakness at elevated temperatures, are removed completely, giving rise to excellent creep and fatigue properties. This is particularly important for turbine blades since they are located nearest to the hot gases coming from the combustion section and experience tremendous thermal and mechanical loads during the turbine operation.

\subsection{Inconel 718}

Inconel 718 is one of the most frequently used nickel-based superalloys worldwide because it maintains superior strength up to $650{ }^{\circ} \mathrm{C}$, as shown in Fig. 5 . It is widely used nowadays for high temperature components in gas turbines, particularly when there is a risk for creep and fatigue damages, for instance, turbine discs in land-based gas turbines.

The heat treatment that is commonly utilized for polycrystalline Inconel 718 is composed of a solution annealing and a two-stage ageing [15]. The solution annealing is conducted at $925-1010^{\circ} \mathrm{C}$ slightly below the solvus of $\delta$ phase, and then quenching in air or in water. In such way, the temperature is high enough to dissolve alloying elements in the matrix, and at a meantime the residual $\delta$ phase at grain boundaries can effectively limit the grain growth. The homogenized alloy is subsequently heated to a temperature within in the range of $718-760{ }^{\circ} \mathrm{C}$ for a certain amount of time in order to precipitate a high volume fraction of the $\gamma^{\prime \prime}$ strengthening phase, and then furnace cooled to a lower temperature, held at $620-649^{\circ} \mathrm{C}$ to continue the growth of the $\gamma^{\prime \prime}$ precipitates, and finally air cooled to room temperature. 


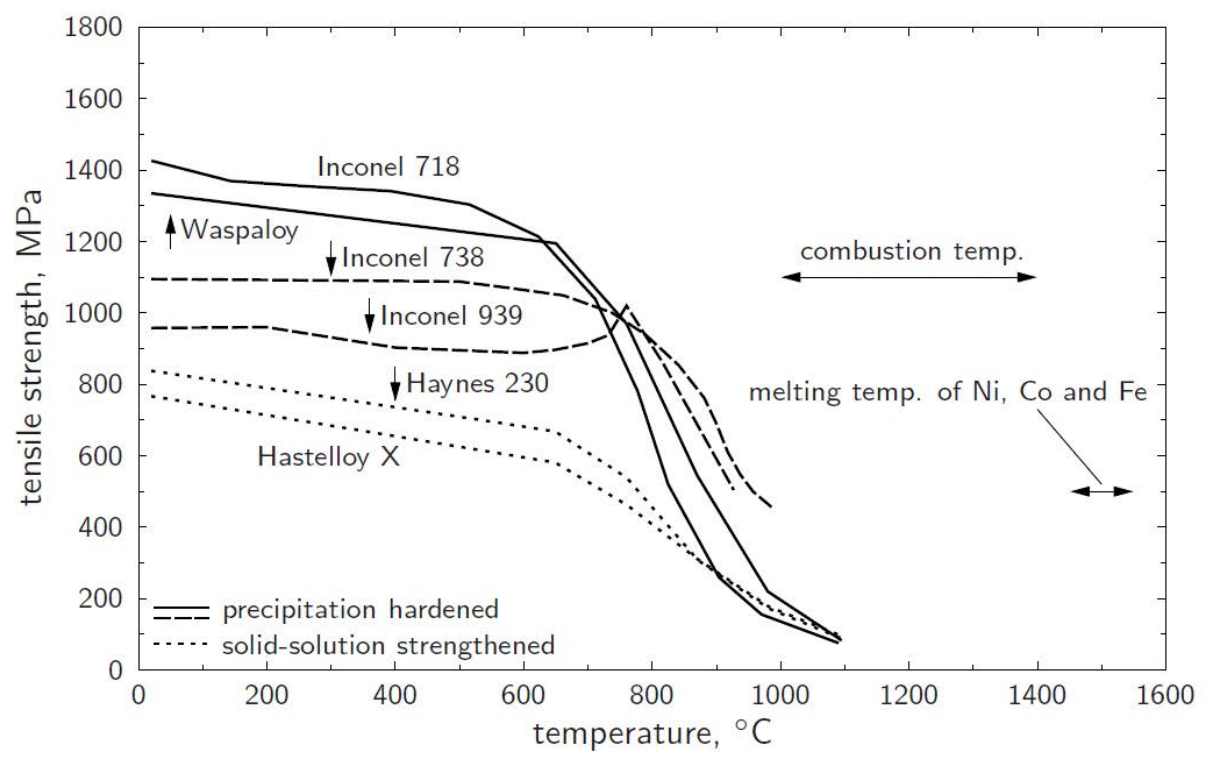

Figure 5. Tensile strength of some commercial superalloys as function of temperature [14].

The strength of the alloy is obtained primarily by the $\gamma^{\prime \prime}$ precipitation. It is only slightly affected by the precipitation of the $\gamma^{\prime}$ [16]. The dominant strengthening mechanism has been related to coherency strains and not to ordering effects [17]. Non-metallic inclusions, such as $\mathrm{NbC}$ and TiN, are often formed during the solidification and they are stable in the microstructure even that the alloy has been homogenized by subsequent heat treatments. Fig. 6 presents a typical microstructure of aged Inconel 718 .

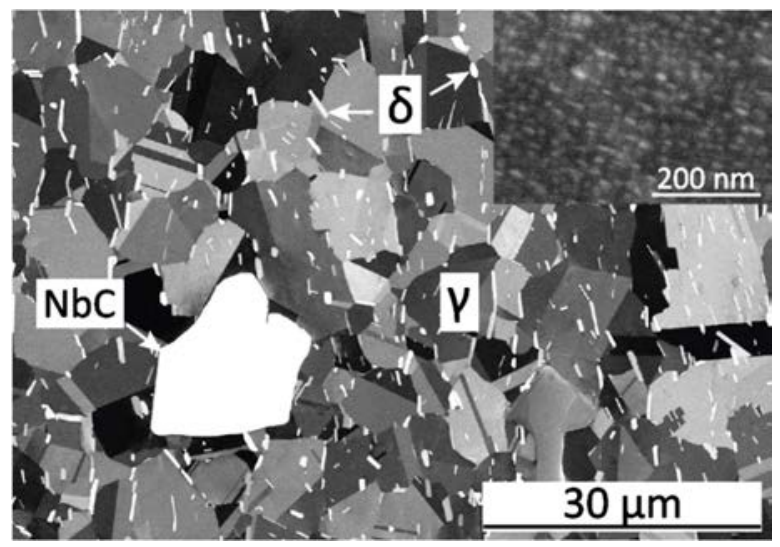

Figure 6. Typical microstructure of aged Inconel 718. It consists of the $\gamma$ matrix, $\delta$ platelets, and primary carbides $\mathrm{NbC}$. Insert showing dispersed $\gamma^{\prime}$ and $\gamma^{\prime \prime}$ precipitates in the $\gamma$ grain. 
The microstructure rapidly degrades in Inconel 718 when thermally exposed at a temperature higher than its ageing temperature. Except for the $\delta$ precipitation with concurrent dissolution of the $\gamma^{\prime \prime}$ strengthening phase as mentioned above, $\alpha-\mathrm{Cr}$ and $\sigma$ phase have also been found in the alloy after long-term thermal exposure at high temperatures above $650{ }^{\circ} \mathrm{C}[18]$.

\section{$3.12 \mathrm{AD} 730^{\mathrm{TM}}$}

The demand for more efficient gas turbines requires the development of new superalloys that are capable of withstanding higher temperatures. One objective for the global leading engine manufacturers is to reach an operating temperature above $700{ }^{\circ} \mathrm{C}$ in the rim sections of the high pressure turbine discs. At this temperature range, Inconel 718 alloy cannot be used anymore due to the rapid $\gamma^{\prime \prime}$ coarsening. AD $730^{\mathrm{TM}}$ is a new nickel-based superalloy, developed by Aubert\&Duval for high temperature turbine disc applications, with terrific combination between cost and mechanical properties. Moreover, the good workability enables it to be manufactured through the cast and wrought $(\mathrm{C} \& \mathrm{~W})$ route [19-21]. Typical microstructure of aged AD $730^{\mathrm{TM}}$ is given in Fig. 7.

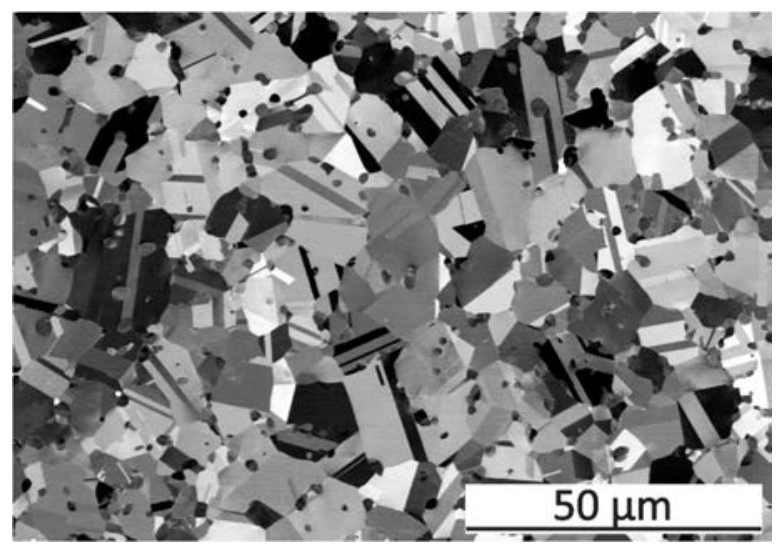

Figure 7. Typical microstructure of aged $\mathrm{AD} 730^{\mathrm{TM}}$.

Compared with Inconel 718 , AD $730^{\mathrm{TM}}$ exhibits better mechanical performance beyond $650{ }^{\circ} \mathrm{C}$ thanks to the precipitation of the $\gamma^{\prime}$ as the primary strengthening phase, instead of the $\gamma^{\prime \prime}$. Udimet ${ }^{\mathrm{TM}} 720 \mathrm{Li}(\mathrm{U} 720 \mathrm{Li})$ is a great challenger to $\mathrm{AD} 730^{\mathrm{TM}}$ which is also strengthened by $\gamma^{\prime}$ phase. However, the alloy is preferably fabricated through the expensive powder metallurgy $(\mathrm{P} / \mathrm{M})$ route due to its low $\mathrm{C} \& \mathrm{~W}$ process capability caused the high $\gamma^{\prime}$ volume content. 718Plus was innovated by ATI ALLVAC and it exceeds the operating temperature capability by $55^{\circ} \mathrm{C}$ compared to 
the conventional Inconel 718 alloy. This modified alloy has a higher content of $\mathrm{Al}+\mathrm{Ti}$ as well as a higher ration of $\mathrm{Al} / \mathrm{Ti}$, which gives rise to a higher volume fraction of the $\gamma^{\prime}$ phase. Meanwhile, the alloy was manufactured with additions of $\mathrm{W}$ and Co instead of Fe and small additions of $\mathrm{P}$ and $\mathrm{B}$, see Table 2, in order to optimize its mechanical properties such as stress rupture and creep resistance. Despite that 718Plus inherits the good workability from the alloy Inconel 718 and presents a moderate raw material cost due to a reasonable cobalt content, its high temperature fatigue and creep resistance is significantly lower than that of U720 Li and AD $730^{\mathrm{TM}}$ alloys [4].

Table 2. Chemical composition (wt\%) of some turbine disc alloys (* ug/g) $[4,20]$.

\begin{tabular}{lcccccccccccc}
\hline \multicolumn{1}{c}{ Alloy } & $\mathrm{Ni}$ & $\mathrm{Fe}$ & $\mathrm{Cr}$ & $\mathrm{Co}$ & $\mathrm{Mo}$ & $\mathrm{W}$ & $\mathrm{Al}$ & $\mathrm{Ti}$ & $\mathrm{Nb}$ & $\mathrm{C}$ & $\mathrm{B}$ & $\mathrm{Zr}$ \\
\hline Inconel 718 & Bal. & 18 & 18 & - & 3 & - & 0.5 & 1 & 5.4 & $250^{*}$ & $40^{*}$ & - \\
718Plus & Bal. & 10 & 18 & 9 & 2.8 & 1 & 1.5 & 0.7 & 5.5 & $250^{*}$ & $40^{*}$ & - \\
U720Li & Bal. & - & 16 & 14.5 & 3 & 1.25 & 2.5 & 5 & - & $250^{*}$ & $200^{*}$ & $300^{*}$ \\
AD 730TM & Bal. & 4 & 15.7 & 8.5 & 3.1 & 2.7 & 2.25 & 3.4 & 1.1 & 0.015 & 0.01 & 0.03 \\
\hline
\end{tabular}

\subsection{Machinability}

Machinability is a term refers to the ease with which a component can be machined to the desired shape with acceptable surface finishing, dimension tolerance, and surface/sub-surface quality [22]. It has always been a challenge when machining nickel-based superalloys [23-26] because:

- These alloys can maintain high strength during machining due to their high temperature properties, with a result that high cutting forces are required;

- The poor thermal conductivity gives rise to a high cutting temperature in the cutting zone;

- The high tendency to rapid work hardening at high strain rates leads to great tool wear;

- Abrasive non-metallic inclusions such as carbides contained in the microstructure cause abrasive tool wear;

- Diffusion wear frequently takes place as a consequence of the high chemical affinity of nickel-based superalloys for many types of cutting tools;

- Welding and adhesion of the workpiece onto the cutting tool often occurs, resulting in deep notches on the machined surface as well as alterations of the tool rake face;

- The high cutting forces could generate vibrations which deteriorate the surface quality. 
The poor machinability generates two basic problems: short tool life and deteriorated surface quality. The surface quality/integrity will in turn determines the performance, reliability, and service-life of the machined workpiece, see Chapter 5. Extreme attentions, therefore, have to be paid to enhance the surface integrity when machining the nickel-based superalloys. 



\section{Machining \& Shot peening}

Machining is a broad term which covers any of various processes in which a piece of raw material is cut into a designed shape and size using a controlled material removal process [27]. It differs from those processes based on controlled material addition, well known today as additive manufacturing. In general, machining can be divided into the following categories:

- Cutting, in which materials are removed by mechanically forcing a single or multiple cutting edges through the workpiece, such as turning and broaching;

- Abrasive machining, such as grinding;

- Nontraditional machining processes, utilizing electrical, chemical, or other sources of energy.

\subsection{Cutting processes}

\subsubsection{Deformation and heat in cutting}

All cutting processes remove materials from a workpiece by establishing a shear zone (the primary shear zone) extended from the cutting edge to the workpiece surface ahead of the cutting tool, as illustrated in Fig. 8. The sharp wedge-shaped cutting tool moves in the direction perpendicular to this cutting edge with a preset depth and speed. The shear plane is orientated at an angle $\phi$ (shear angle) with the newly generated surface, which can be derived from the following expression [28]: 
$\tan (\phi)=\frac{\frac{a_{0}}{a_{c}} \cos \alpha}{1-\frac{a_{0}}{a_{c}} \sin \alpha}$

where $a_{0}$ represents the un-deformed chip thickness, $a_{c}$ represents the deformed chip thickness, and $\alpha$ represents the fixed rake angle.

The deformation behavior in the primary shear zone is dominated by complex coupling of the two processes, strain hardening and thermal softening. When strain hardening predominates, uniform plastic deformation occurs in the shear plane, which results in continuous chip formation. Once the material hardening is overtaken by thermal softening due to the great local heat accumulation in the shear zone, localized shear deformation will take place in a narrow band where the material has been softened. The shear band will be further localized by the continued deformation heating, and ever higher strains and temperatures will be attained in this narrowing band, which is often referred to as "adiabatic shear band" [29]. Such localization of plastic flow in the primary shear zone often takes place when machining materials with limited slip systems, low conductivity, and superior strength, such as titanium alloys and nickel-based superalloys. This is particularly the case in the high-speed cutting. Both experimental observations and analytical modelling have shown that when cutting aged Inconel 718 at relatively low speeds, continuous chips were formed, whereas the chips became serrated with localized shear bands between the segments with increasing cutting speed [30,31].

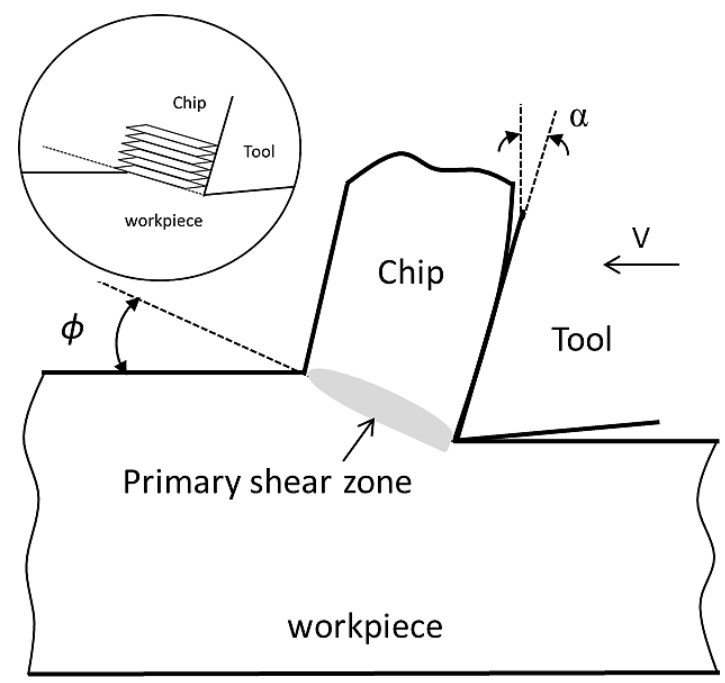

Figure 8. Schematic illustration showing the shear deformation during orthogonal cutting. 
The heat generated during a cutting process is to a large extent originated from the plastic work done in the primary shear zone [32]. The local heating in this zone results in a high temperature gradient, which allows adiabatic shear deformation, as mentioned above. Moreover, heat is created due to the energy input at the tool-chip interface in terms of deforming the chip and overcoming the sliding friction. At the tool-workpiece interface, the rubbing contact (friction) between the tool flank face and the newly developed surface of the workpiece also generates substantial heat during the cutting.

\subsubsection{Broaching}

Broaching is regarded as a machining method of choice when manufacturing components with complex features at tight dimensional specifications. It is also a highly productive machining process since the broach performs a sequence of roughing, semi-finishing, and finishing cutting in one pass. There are two main types of broaching that are widely used nowadays: linear and rotary. Linear broaching is a more common process in which the cutting tool, i.e. the broach, moves linearly against a surface of the workpiece to be manufactured, while in rotary broaching, the broach is rotated and pressed into the workpiece to form an axis-symmetric shape. In turbo machinery industries, broaching has been successfully applied for decades. The most important application is to machine those fir-tree root fixings on gas turbine discs for blade mounting. A schematic illustration is presented in Fig. 9.

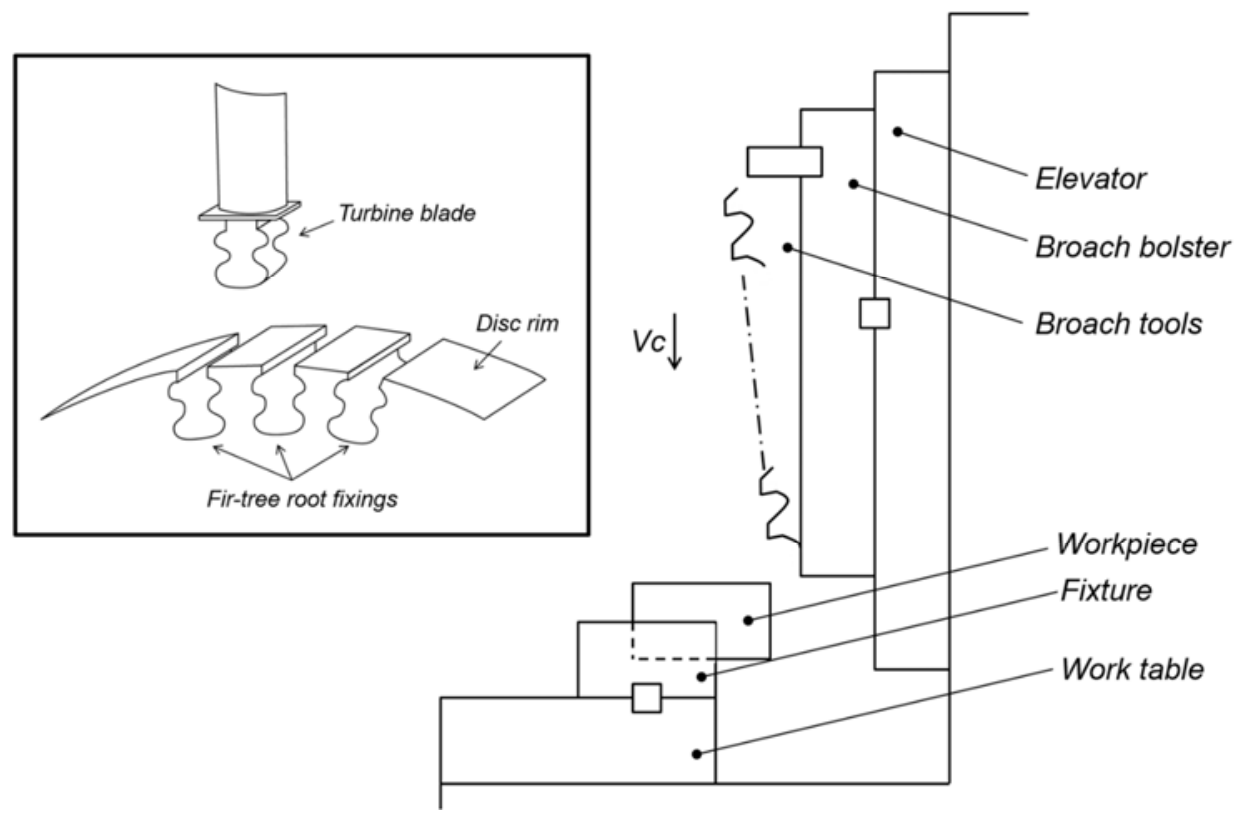

Figure 9. Broaching of fir-tree root fixings on the rim of a turbine disc for blade mounting. 
The process starts by clamping the disc to the work-holder placed on the work-table. The broach initially stays at the start position above the work-holder, and then the elevator lowers the broach through the edge of the disc with a controlled cutting speed. The disc is held stationary, and the broach strikes linearly against it without any rotations. Once the broach goes through completely, the disc is withdrawn from the cutting position and the broach is raised up back to its start position. The cutting tool material that is commonly used for broaching is high speed steel (HSS), which provides great wear resistance and can be easily manufactured to obtain the required cutting edge profile. However, when broaching gas turbine discs made of difficultto-cut materials such as Inconel 718, The cutting speeds are limited in a range of $V_{c}$ $=2-8 \mathrm{~m} / \mathrm{min}$ to guarantee a good surface quality and tight geometric tolerance.

The most critical characteristic of a broach is the rise per tooth (RPT), see Fig. 10. A broach has many teeth and the height of the teeth increases over the length of the tool. The feed/depth of cut, therefore, is built into the broach, distinguished from all other machining processes. A broach is usually comprised of a set of several segments mounted in a specifically designed holder, while the RPT varies for each segment of the broach. One broach is specially designed to cut just one profile; the peripheral shape of the last segment of the broach is the inverse of the final shape of the feature to be machined.

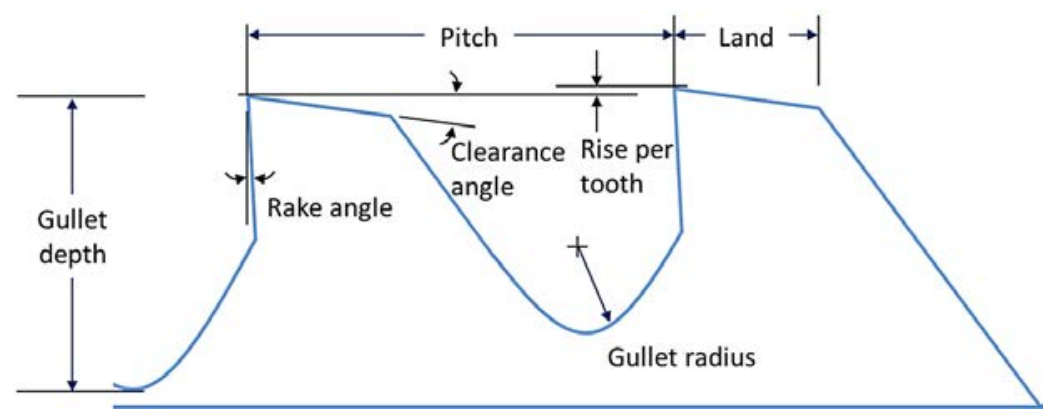

Figure 10. Basic design of a broach in the case of linear broaching.

\subsubsection{Turning and milling}

In addition to broaching, another two cutting methods, turning and milling, are also widely used in the manufacturing of turbine components. Turning is a cutting process that produces cylindrical parts, such as turbine shafts. It cuts an external surface by rotating the workpiece, using a single-point cutting edge, and feeding the cutting tool in parallel to the longitudinal axis of the workpiece, as illustrated in Fig. 11. 


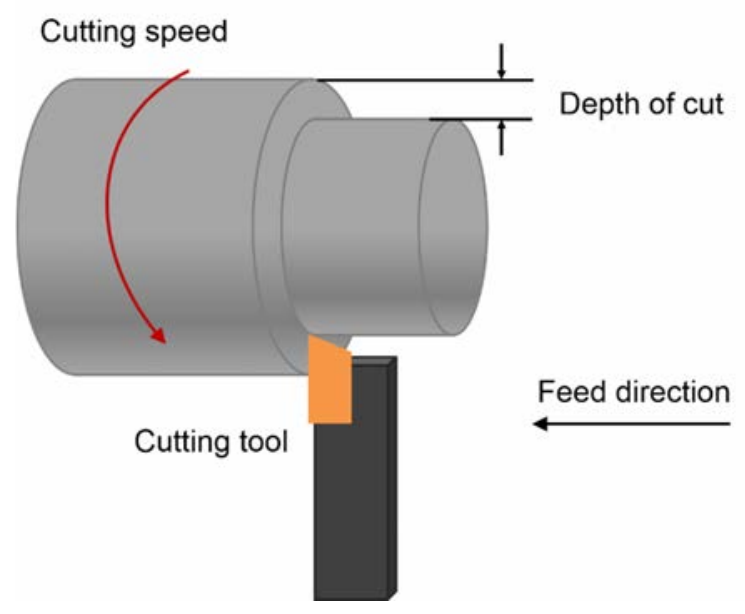

Figure 11. Cutting conditions for a turning operation.

In recent years, milling and wire electrical discharge machining (WEDM), as more flexible machining techniques, have been intensively discussed in turbo machinery industries as alternatives other than broaching for the production of complex slots on turbine engine components $[33,34]$. More introduction with respect to the process of WEDM will be given in the next Section 4.2.

Milling is a process of cutting away materials by feeding a rotary cutter with multiple cutting edges past the target surface. It comprises of three basic types, face milling, peripheral milling, and end milling, as illustrated in Fig. 12.

In the face milling, the cutter is mounted on a spindle which has its axis of rotation perpendicular to the surface to be machined. The cutting edges are mostly located on the face of the cutter. Face milling is usually used to cut flat surfaces or flatbottomed cavities. As a comparison, the spindle axis of rotation is generally in a plane parallel to the workpiece surface in the peripheral milling, and the cutting teeth are located on the periphery of the cutter body. Peripheral milling is well suitable to cut a part with a more complex geometry such as deep slots, threads, and gear teeth. In the end milling, the cutter generally spins with an axis perpendicular to the workpiece surface, but it can be tilted to cut tampered or wedge-shaped surfaces. The cutting edges are located both on the end face and the periphery of the cutter body.

With the development of high performance cutting tools, the cutting speed in turning and milling has been greatly increased. Ceramic and cubic boron nitride (CBN) tools are adequate for high speed machining of nickel-based superalloys due to their superior hot hardness and good wear resistance [26]. In addition, protective coatings are also developed and applied on the cutting tools to provide better performance and durability in high speed machining. 


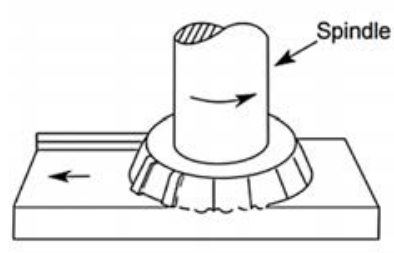

(a)

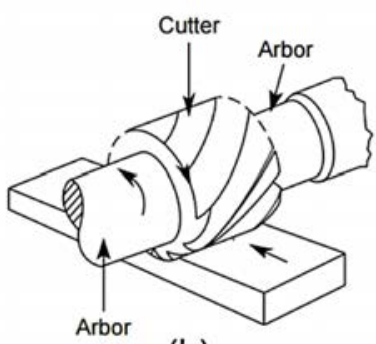

(b)

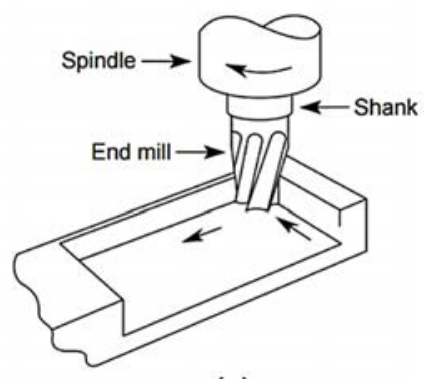

(c)

Figure 12. Basic types of milling cutters and operations: (a) face milling, (b) peripheral milling, and (c) end milling [35].

\subsection{Wire electrical discharge machining}

Wire electrical discharge machining (WEDM), as illustrated in Fig. 13, is a competitive alternative to cut high strength materials such as nickel-based superalloys as it is based on thermal-electric energies between an electrode (a brass wire) and the workpiece, regardless of the hardness or the strength of the material to be machined [36]. In addition, WEDM also allows machining of components with a complex geometry. A further advantage of the WEDM is that little plastic deformation is induced beneath the WEDM cut surface since there is no contact between the electrode and the component during machining.

However, the giant heat generated in EDM causes melting and even evaporation of the workpiece material on the machined surface. As a consequence, a surface recast layer or a surface white layer accompanied with tensile residual stresses is frequently formed during the subsequent rapid cooling [37-40]. The structure and hardness of this layer differs from that of the bulk material. It commonly consists of micro-voids and micro-cracks due to either the enormous thermal stress or the tensile stress during the cooling process. These surface integrity issues existing on a WEDM cut surface inevitably have a detrimental effect on the fatigue resistance of the workpiece $[41,42]$. However, studies also pointed out that a better fatigue life could be obtained by optimizing the input energy of the process (working voltage, current, pulse-on duration, etc.) [43], which could be even close to the lifetime obtained from the broached case [44]. 


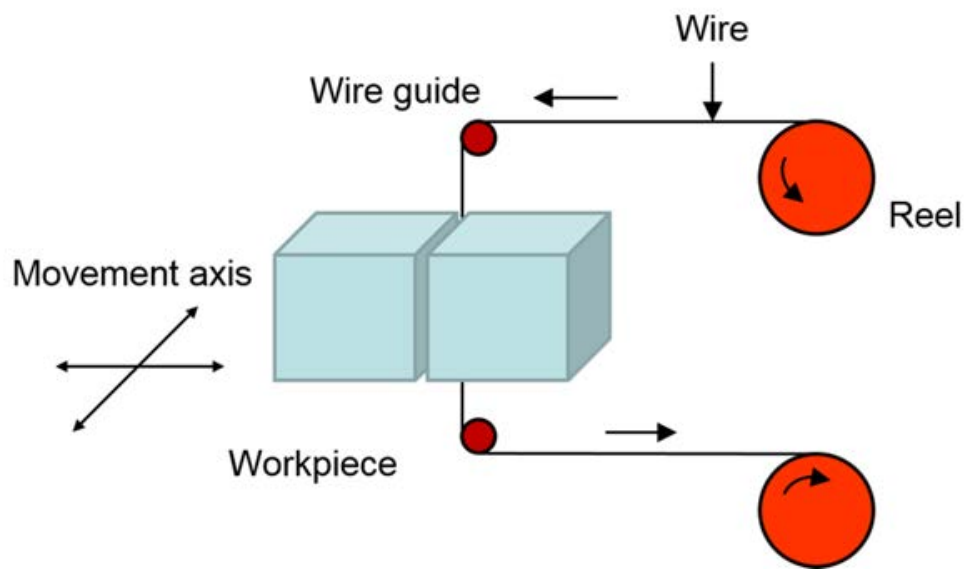

Figure 13. A schematic illustration of the wire electrical discharge machining process.

\subsection{Shot peening}

In turbo machinery industries, post-machining surface treatments, such as shot peening, have become a critical step at the final stage of the production. Shot peening is a cold work process by which the surface texture induced by machining, the machining marks, for example, can be annihilated, and more importantly compressive residual stresses are induced on the treated surface. The impingement of a stream of shots, directly at the surface with high velocity and under controlled conditions, causes local yielding of the surface material, and compressive residual stresses are generated due to the constraint of the material underneath, as illustrated in Fig. 14. Various intensities of surface compression could be created on the shotpeened product, depending on the component material and geometry, shot media and quality, impact angle, and peening intensity, coverage, and duration [45].

Shot peening confers high resistance to fatigue failure [46-49] and to some forms of stress corrosion [50,51]. This contributes to its wide applications on the key components used in turbine engines in order to ensure the safety when the engine is under operation and also to increase the engine life. The benefits of shot peening are primarily originated from the compressive residual stresses induced in the shotpeened layer. These beneficial effects could be retained only if the surface compression remains stable during service at the engine temperature. Thus, great insights to the stress relaxation behavior and mechanism in shot-peened alloys under thermal, mechanical or a combined impact is of significance. The use of laser to induce compressive residual stresses on the surface of a component, i.e., laser shock peening, is becoming a competitor to shot peening since it can produce a deeper 
compressive zone with higher thermal stability. Although the laser peening is already an engineering production process rather than a laboratory test nowadays, however, due to its high cost and complicated setups, it is only being used for surface enhancement of the core parts served in aero engines.

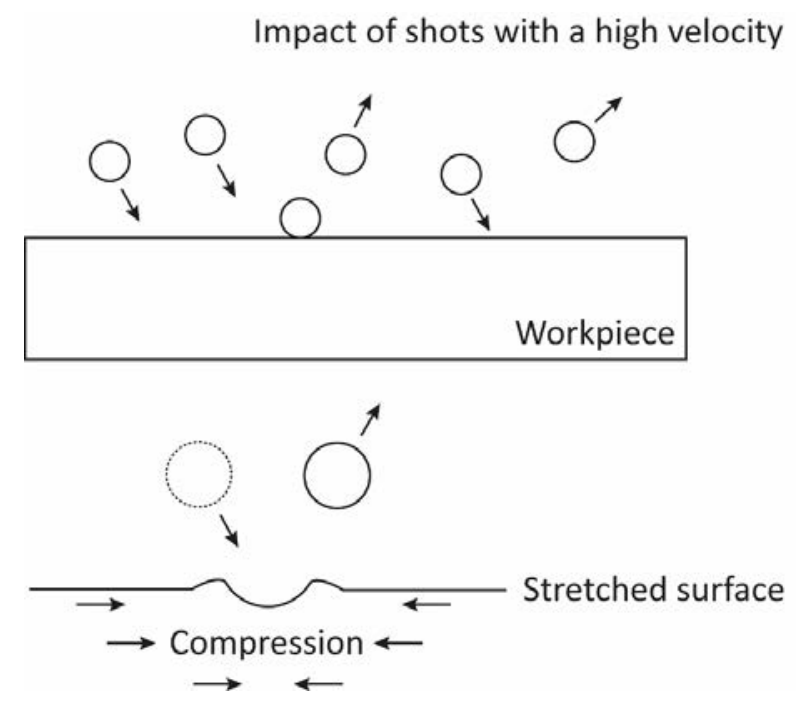

Figure 14. Mechanism of compressive residual stresses induced by shot peening. 


\section{5}

\section{Surface Integrity}

The concept of surface integrity was first defined in a technical sense by Field and Kahles [52] as the inherent or enhanced condition of a surface produced by machining processes or other surface generation operations. With this concept, not only machining, all processes which introduce changes to a surface can affect the surface integrity, e.g., surface treatments such as shot peening and heat treatments at elevated temperatures. Surface integrity includes various aspects which can be generally classified into the following three categories [24]:

1. Surface topography, including surface texture, roughness, and formation of surface defects;

2. Surface metallurgy, such as plastic deformation, recrystallization, and precipitation;

3. Mechanical characteristics, typically in the form of micro-hardness and residual stresses.

The quality and performance of an engineering product can be greatly influenced by its surface integrity. This is particularly the case when fatigue properties, stress corrosion resistance, tribological behavior (e.g. friction and surface wear), as well as dimensional accuracy are of great importance for component applications [53].

\subsection{Surface topography}

Surface roughness has been considered to be the primary indicator of the surface integrity of a workpiece, and in most cases, is widely used as a quality specification for manufacturers. Surface roughness is normally characterized by central line 
average $\left(R_{a}\right)$, maximum profile height $\left(R_{t}\right)$, and ten-point average $\left(R_{z}\right)$. The achievement of desired surface roughness is not only essential to the subsequent assembly, but also plays a pivotal role in determining the fatigue life and strength of the workpiece [54]. It has been shown that fatigue cracks are usually initiated from persistent slip bands or at grain boundaries if the specimen has low surface roughness, for instance, a specimen with a polished surface $[54,55]$. However, the micro-notch effect on a rougher surface will lead to a local plastic strain field when an external load is applied due to stress concentration. This zone of plasticity in which fatigue cracks are preferable to be initiated endangers the fatigue life of the specimen.

During machining, various forms of surface defects could be created. Feed marks, chip re-deposition, and grain deformation are normally the ones in the largest scale on a machined surface, and therefore are considered to be the major surface defects. In addition, most nickel-based superalloys consist of non-metallic inclusions. Cracking and plucking of these hard particles and their re-deposition on the surface can lead to surface cavities and subsequent smearing, dragging, and even tearing during the next pass from the surface. As shown in Fig. 15, carbide cracking commonly takes place when machining the alloy Inconel 718 [11,56], and it produces multiple cavities on the machined surface which favors the formation of fatigue cracks. The presence of surface defects leads to high surface roughness, even though they can be reduced by selecting suitable cutting parameters based on the properties of the material to be machined $[57,58]$, however, complete elimination of such negative effects on surface integrity is not possible.
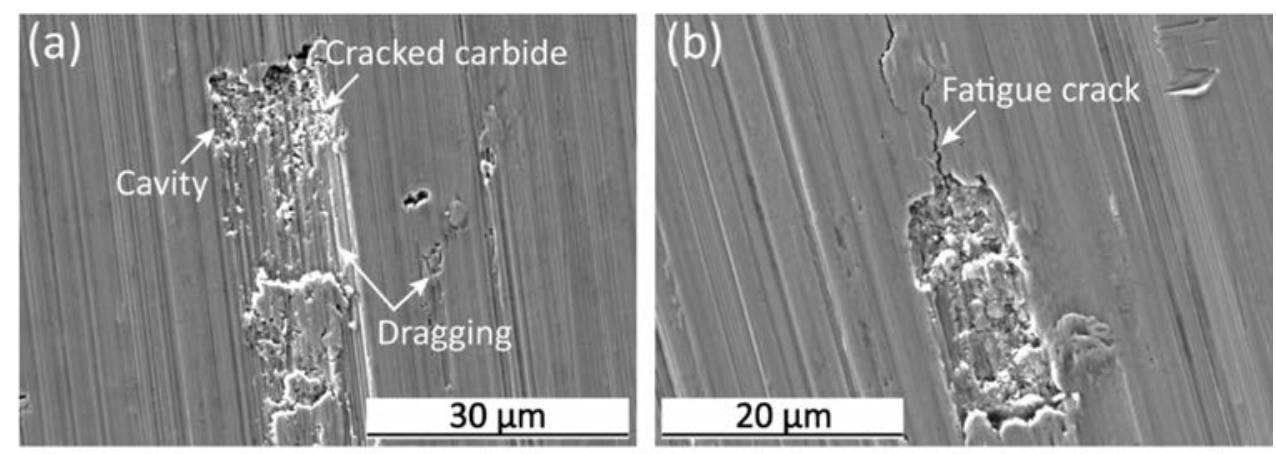

Figure 15. (a) Surface cavity and debris dragging on milled surface of Inconel 718 associated with carbide cracking. (b) An example showing crack initiation at the surface cavity when subjected to fatigue loads. 


\subsection{Surface Metallurgy}

Traditional cutting processes cause plastic deformation with gradually reduced intensity from surface to sub-surface regions. Work hardening of the surface and sub-surface microstructure occurs as the response to the excessive plastic strains. The work-hardened layer increases the difficulty of the subsequent cuts, and therefore is detrimental to the surface integrity of the final product. Such workhardening phenomenon can be successfully captured by progressively measuring indepth micro-hardness beneath the machined surface. An increase from the lower bulk hardness to a higher surface hardness has been observed on plenty of machined titanium alloys and nickel-based superalloys [59-61], while the increment becomes more evident in nickel-based superalloys since they usually exhibit higher workhardening tendency.

The severity of the plastic deformation on a machined component is influenced by many factors such as 1) cutting parameters, cutting speed, feed rate, and depth of cut, for instance, 2) tool parameters including tool material, rake/clearance angle, tool geometry, and tool wear, etc., and 3) material properties, e.g., microstructure, grain size, and mechanical strength. Among these factors, the tool wear has been found to be a dominant cause which results in severe plastic deformation [62]. When machining Inconel 718 at cutting speeds, $V_{c}=32-56 \mathrm{~m} / \mathrm{min}$ with a feed rate, $f=0.13-$ $0.25 \mathrm{~mm} / \mathrm{rev}$, no significant plastic deformation was observed after $1 \mathrm{~min}$ of turning, whereas prolonged turning of 15 min resulted in remarkable plastic deformation as the tool wears.

During plastic deformation, a fraction of the mechanical energy is stored in the deformed microstructure, in the form of dislocations, twins, stacking fault, etc., while the rest is converted into heat. Hence, in metal cutting, the surface material is not only subjected to mechanical stress/strain, but also simultaneously to thermal impacts, and under some circumstances even subjected to chemical energies. These effects may lead to further microstructural alterations, such as thermal deformation, phase transformation, and white layer formation.

The white layer was first reported in steel wire ropes [63]. This layer resists against standard etchants and appears white and metallurgically featureless under optical microscope and scanning electron microscope. Using transmission electron microscope and X-ray diffraction, it has shown that this layer is frequently comprised of a ultra-fine grain structure $[29,64,65]$, see for example in Fig. 16. Three dominant contributory mechanisms have been suggested for the formation of white layers [23]:

- Rapid heating and quenching which leads to phase transformation;

- Surface reaction with the environment; 
- Plastic flow which generates a homogeneous structure or one with a fine grain structure.

Surface white layers are mostly harder than the bulk material, but at a meantime they are brittle and normally accompanied with tensile residual stresses. As a consequence, the formation of a white layer is undesirable since it eases crack initiation and propagation especially when subjected to fatigue loads [66,67]. Many studies have shown that high cutting temperatures facilitate the white layer formation, e.g., when cutting at high speeds, without external cooling, or using worn tools $[64,65,68,69]$. Under such aggressive cutting conditions, an increased temperature gradient is created on the machined surface due to the large plastic work, high strain rate, and intense friction [32].

The formation of white layers have also been widely observed on the components produced by electrical discharge machining. The giant heat generation, as the nature of the process, causes melting and even evaporation of the surface material, and the white layer is formed during subsequent rapid cooling $[37,41,70]$.

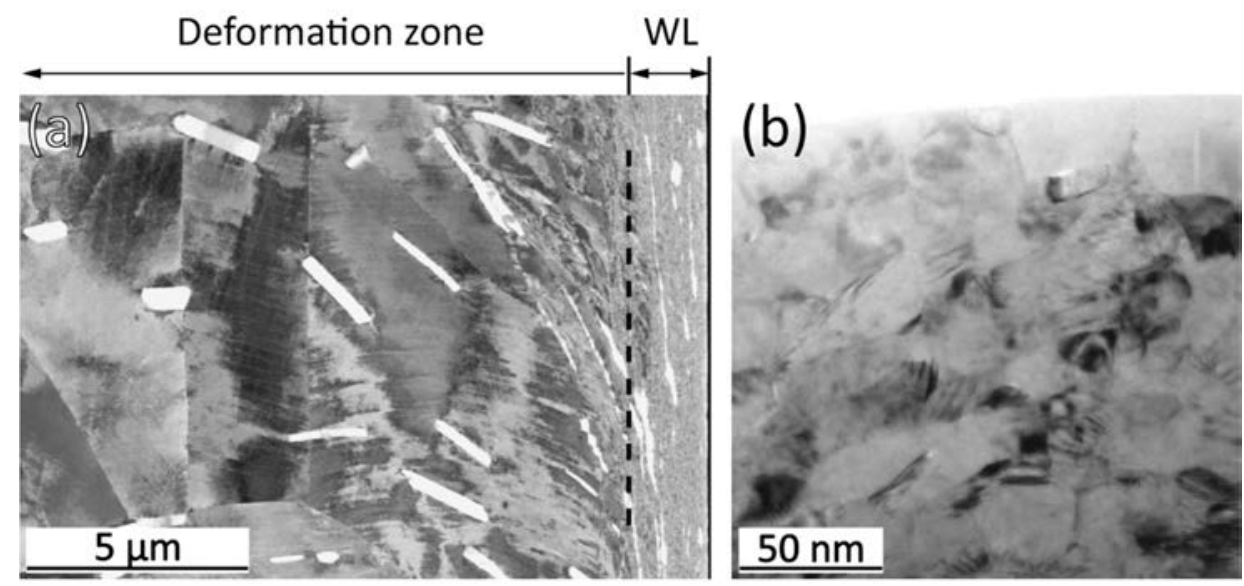

Figure 16. White layer (WL) formation on broached surface of Inconel 718. The microstructure is irresolvable under scanning electron microscope (a). Using transmission electron microscope, it confirms that this layer is comprised of nano-sized grains (b).

Dependent on the material to be machined and the machining process specifically employed, the underlying mechanism for white layer formation changes. In turning of hardened steels, the quenching mechanism of rapid heating and cooling was found to be of predominance in which the surface material was transformed from austenitic to martensitic structures [71-73]. Instead of the quenching effect, it has also been suggested that the white layer is formed by adiabatic shear localization when turning AISI 4340 [64] or broaching Inconel 718 (see Paper III) as the similarity of the 
structure and crystallography characterized in the white layer in comparison with that observed in the adiabatic shear bands formed during high strain rate deformation. Given its detrimental effects on fatigue properties, studies on the mechanism for white layer formation and how to minimize the thickness of this brittle layer is of utmost significance.

\subsection{Residual stresses}

Residual stresses are stresses that remain in a solid material after the original loading has been removed. They originate from elastic response to inhomogeneous distribution of non-elastic strains, i.e. misfits between different regions, different parts, or different phases [74,75]. These misfits are mostly caused by non-uniform plastic deformation, phase incompatibility, and thermal gradients. Component failure can take place by the combined effect of applied and residual stresses. Compressive residual stresses are generally beneficial, while tensile residual stresses should be avoided since they are superimposed with the applied stress, raising the risk of catastrophic failure. For instance, a shorter fatigue life is commonly obtained when tensile residual stresses are present because the mean stress and stress amplitude which drive the initiation and propagation of fatigue cracks have been increased. Compressive residual stresses are sometimes introduced deliberately to enhance the surface integrity, as in shot-peening, laser peening, roller burnishing, etc.

The residual stress formation in machining processes is considered to arise from a competing mechanism of mechanically and thermally induced deformation. Mechanically induced deformation could give rise to either tensile or compressive residual stresses, depending on the deformation behavior that occurs at the tool/workpiece contact surface. If the compressive plastic deformation ahead of the tool tip is lower than the tensile one behind it, as illustrated in Fig. 17, the surface material consequently will undergo overall tensile plastic deformation, thereby resulting in compressive residual stresses, and vice versa. If the thermal stress generated due to cutting heat causes plastic deformation of a surface layer, tensile residual stresses will be induced in the layer after cooling. The mechanically and thermally induced residual stresses always exist simultaneously where the relative significance varies from one process to another [76].

When machining titanium and nickel-based alloys, residual stresses are often more tensile at the surface of the workpiece, and gradually change to be compressive as the depth increases $[23,24,77,78]$. However, like other aspects of surface integrity, the residual stress induced by machining also depends on the cutting and tool parameters. Fig. 18 shows a variation of the residual stresses in a broached fir-tree slot from tension on the flank surface of the second tooth to compression at the flat 
bottom. It is important to remove tensile residual stresses either by preventing them from occurring during machining, or by post-machining surface treatments during which compressive residual stresses are induced.

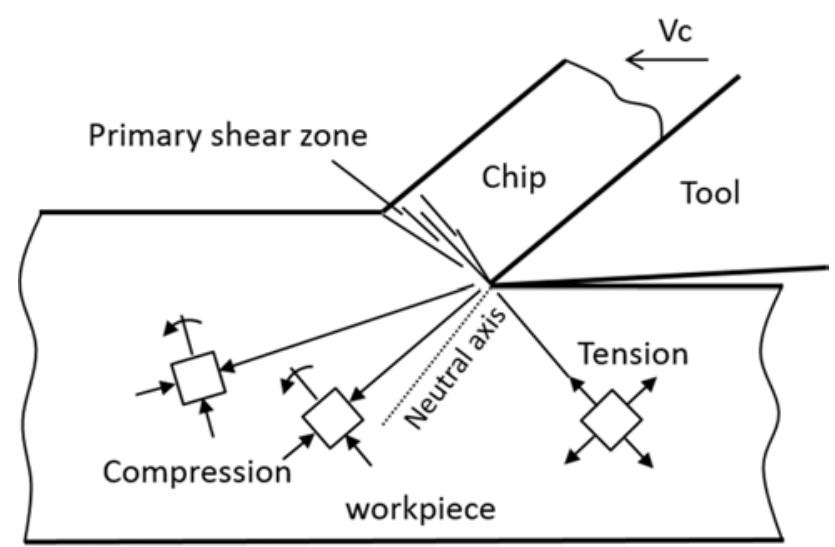

Figure 17. Origin of mechanically induced residual stresses.
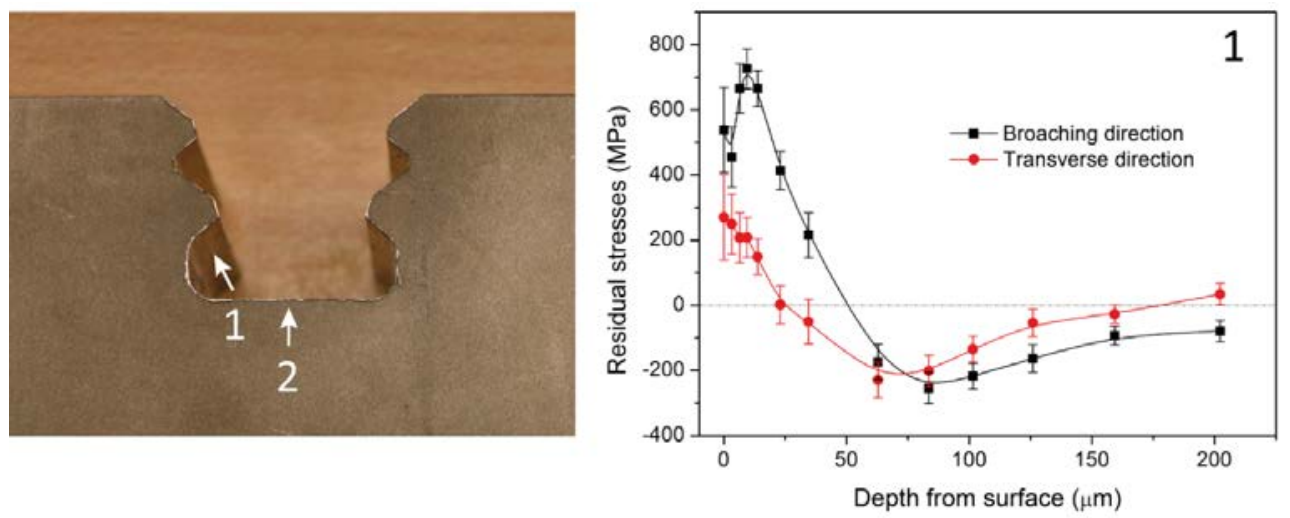

Figure 18. Residual stress distribution at different regions of a broached firtree slot of Inconel 718.

Region 1: flank surface of the second tooth; Region 2: flat bottom.

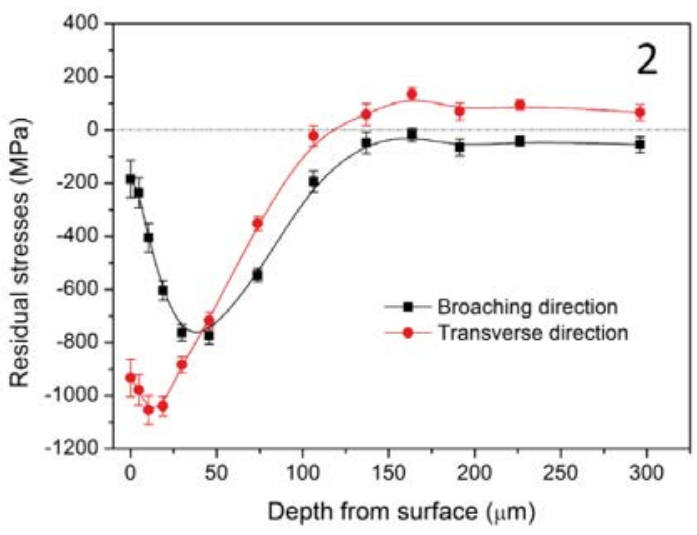


High residual stresses produced by machining may also cause dimensional instability of the workpiece. The dimensional instability is basically a change in dimension with respect to time without any work being done on the part. This phenomenon brings problems in structural assembly, as it destroys the structural integrity. Inconel 718 has revealed the dimensional instability after machining, and it is more prone to dimensional changes in comparison with both titanium alloys and mild steels $[79,80]$.

\subsection{Effect of thermal exposure}

Most of the engine components made of nickel-based superalloys are exposed to elevated temperatures during service. Due to the mechanical energy stored in the highly deformed surface microstructure, machined components with or without post-machining surface treatment are prone to microstructural changes when subjected to thermal impacts. Two thermally activated processes are frequently observed in deformed metals: thermal recovery at relatively low temperatures during which annihilation of metastable lattice defects as well as dislocation rearrangement and annihilation usually take place, and recrystallization at higher temperatures [81]. As shown in Fig. 19, in some cases undesirable precipitation can also take place, which is facilitated by the substantial defects in the deformed microstructure [11].

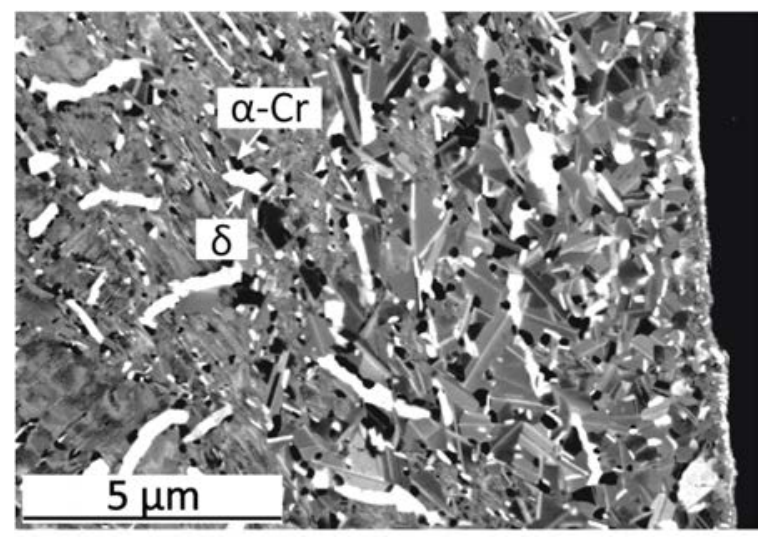

Figure 19. Surface recrystallization and $\alpha$-Cr precipitation on shot-peened surface of Inconel 718 after $3000 \mathrm{~h}$ thermal exposure at $600^{\circ} \mathrm{C}$. As illustrated, $\alpha$-Cr precipitates mostly in the vicinity of the $\delta$ phase.

The microstructural alterations will inevitably result in changes in surface mechanical properties as well as residual stress state. Complete relaxation of the beneficial compressive residual stresses induced by shot peening can be expected once the temperature is high enough to trigger the occurrence of surface recrystallization, see 
Paper IV included in this thesis. In addition, a hardness reduction within the surface work-hardened layer has been commonly observed after thermal exposure as a consequence of the annihilation of dislocations $[55,82]$. These thermal effects on surface integrity are extremely important when high fatigue resistance and tight tolerance of component dimensions are strongly required for high temperature applications. 


\section{Fatigue}

\subsection{Introduction}

Fatigue of materials refers to the changes in material properties which can occur as a result of the repeated application of stresses or strains [83], especially to those changes which lead to cracking or fracture failure. Fatigue failure consists of many different forms:

- Mechanical fatigue caused by external stresses or strains;

- Creep-fatigue when cyclic loads applied in association with high temperatures, especially when there exists a long dwell time;

- Thermomechanical fatigue, taking place if the temperature of the cyclically loaded component also varies;

- Sliding or rolling contact fatigue caused by cyclic loads which originate from sliding or rolling contact between two materials;

- Fretting fatigue which occurs as a result of the cyclic shear stress produced by friction due to relative small oscillatory motion on two surfaces in intimate contact with each other.

In addition, based on the number of load cycles, there exists another conventional distinction of fatigue failure, i.e., low cycle fatigue (LCF)-up to $10^{5}$ cycles to failure, high cycle fatigue (HCF)-between $10^{5}$ and $10^{8}$ cycles to failure, and very high cycle fatigue (VHCF)-over $10^{8}$ cycles to failure. The physical rationale behind this distinction is the region of the stress-strain curve where the repetitive load and resultant strains are taking place. In the case of LCF, the applied stress exceeds the 
yield strength of the material, and plastic deformation normally occurs. In this circumstance, the accounting of the strains in the material offers more accurate description. In HCF and VHCF, the stress is low where the stress-strain relation can be considered to be elastic. The fatigue failure, therefore, is commonly stress controlled.

Fatigue failure is normally unexpected and could cause catastrophic consequence since it generally takes place as influenced by cyclic loads whose peak values are much smaller than the "safe" load level estimated based on static fracture analyses.

\subsection{Crack initiation}

The origin of fatigue cracks in metals and alloys as ductile solids of high purity is frequently rationalized by the classic mechanism based on cyclic deformation induced surface roughening, first proposed by Wood [83]. The surface roughening is visualized by microscopic hills and valleys, commonly referred to as extrusions and intrusions, at the sites where slip bands appear at the surface. These slip bands are formed due to the accumulation of cyclic slip irreversibilities and well known as persistent slip bands (PSBs). Fatigue cracks are preferably developed from the roughened surface, in particular at the root of the valley due to stress concentration. Direct microscopic observations also revealed that the PSB-matrix interface is also a preferential site where fatigue cracks may initiate. It is due to the fact that the strains in PSBs are highly inhomogeneous and localized at the PSB-matrix interface $[84,85]$. In some cases, fatigue cracks can also start at grain boundaries, twin boundaries, or inclusions which impinge on the PSBs because of the local plastic incompatibility and stress concentration [86-88].

As for the materials which contain substantial surface and internal inclusions, fatigue crack initiation at these particles is often observed mostly due to their low toughness compared with the matrix [89-95]. The inclusions are more easily broken than the bulk material, and present as stress concentration. However, when fatigue cracks are initiated at inclusions, whether the formed crack may grow and lead to a short fatigue life depends on the inclusion type, size, and distribution, as well as the residual stresses in the particles and matrix. Fractographic observations have revealed the crack initiation at surface and sub-surface non-metallic inclusions such as carbides, nitrides, and carbonitrides, when the alloy Inconel 718 is subjected to low-cycle fatigue with low-strain amplitude at intermediate temperatures [96]. Instead of inclusions, fatigue crack initiation at other metallurgical weak sites like porosities is also fairly common in cast alloys and powder-metallurgy alloys [97-101]. Such phenomena are most evident in VHCF. A transition of the crack initiation site from 
specimen surface to sub-surface/internal pores and inclusions takes place as decreasing the load level $[89,102]$.

Crystallographic anisotropy, i.e., material texture, is another factor which could strongly affect the initiation of fatigue cracks. It has been found in nickel-based superalloys and titanium alloys that fatigue crack initiation takes place at both slip bands and grain boundaries in a cluster of grains which have similar crystallographic orientations [103-106]. This local texture enables easy slip transmission across lowangle grain boundaries such that the grain cluster acts like a single grain, giving rise to a larger slip distance, more dislocation pile-up, and larger stress concentration at grain boundaries.

As described at the beginning of this section, fatigue crack formation mostly takes place on the surface of a component, especially at the sites where stress concentration is present. Machined surfaces are normally rough, and the micro-notches given by the high roughness could generate localized plastic strains, and thereby facilitate the fatigue crack initiation. Some empirical and analytical models evaluate the effect of machined surface roughness on the fatigue life of the component by using conventional notch fatigue analyses [54,107,108]. They estimate the stress concentration factor and notch sensitivity factor based on the characteristic width, depth, and root radius at the surface micro-notch. When machining under aggressive conditions or machining high strength materials, like nickel-based superalloys, more surface integrity issues, such as cavities, micro-cracks, tensile residual stresses, and white layer formation, could be created on the machined surface. The pre-existing surface cavities and micro-cracks provide multiple preferential sites where fatigue cracks may initiate, or could even start to grow without an incubation of nucleation, thereby commonly resulting in a short fatigue life, see Paper V and VII for example. Tensile residual stresses also facilitate fatigue crack initiation as they are superimposed on the external stress, and thereby lead to an increased driving force. White layer formation normally takes place accompanied with exhaustion of surface ductility, generation of tensile residual stresses, and presence of cavities and microcracks. Therefore, great efforts have been dedicated to annihilate white layers in order to obtain a high resistance to fatigue crack initiation. This is particularly the case on the machined surface produced by EDM [36,38,39,109-111].

It is common to enhance the surface integrity of machined components by shot peening for the purpose of retarding surface crack initiation during fatigue. As seen in Paper V of this thesis and $[47,48]$, sub-surface crack initiation corresponding to the depth of the compressive layer is widely observed on various shot-peened materials when subjected to fatigue loads. This leads to an increased fatigue life of the material. The beneficial effects of shot-peening are considered to primarily arise from the compressive residual stresses induced in the shot-peened layer. However, 
it is believed that the elimination of surface marks and defects, modification of surface roughness, and introduction of surface work-hardening by the process could also partly contribute to the retardation of surface crack initiation during fatigue. Given the importance of the surface compressive residual stresses, thermal exposure or cyclic plastic-strains can reduce or even completely remove the benefit of shot peening if it causes significant stress relaxation. The studies on shot-peened Inconel 718 in this thesis project have shown that once the surface compression has been largely relaxed by thermal exposure, sub-surface crack initiation vanished and fatigue cracks were created at the shot-peened surface, leading to a reduction of the fatigue life, see Paper VI,.

When a cyclically loaded component is exposed to elevated temperature and aggressive medium, the environmental attack at selective surface locations may provide preferential nucleation sites for fatigue cracks, e.g., oxidation eruption, corrosion pits, and debonded grain boundaries. In most cases, the environmentally assisted crack initiation causes a rapid fatigue failure of the material [112-114].

\subsection{Crack propagation}

Once a crack is formed under cyclic loading conditions, the fatigue failure is preceded by a substantial amount of crack propagation, initially within a few grains (short crack growth), and then into a stable stage where the rate of growth of the fatigue crack can be expressed in terms of the crack length increment per cycle, $\mathrm{d} a / \mathrm{d} N$. Based on linear elastic fracture mechanics, Paris, Gomez \& Anderson [115] and Paris \& Erdogan [116] suggested that the fatigue crack increment $\mathrm{d} a / \mathrm{d} N$ in ductile materials is related to the stress intensity factor range $\Delta K$ by the power law relationship, which is well known as the Paris's law:

$\frac{d_{a}}{d N}=C \Delta K^{m}$

The Paris power law relationship proposes a linear variation of $\log \mathrm{d} a / \mathrm{d} N$ against $\log$ $\Delta K$, which pertains to a portion of the total fatigue crack growth curve commonly seen for most metallic alloys, see Fig. 20. At values of $\Delta K$, both below and above that of the Paris regime, one can see a steep rise in crack propagation rate with increasing $\Delta K$. In regime $\mathrm{A}$, when the stress intensity factor range is below the threshold value $\Delta K_{\text {th }}$, fatigue cracks either keep dormant or grow at undetectable rates, while above the threshold it shows a sharp increase of the $\mathrm{d} a / \mathrm{d} N$ with the increased $\Delta K$. At the final step of the propagation, i.e., in regime $\mathrm{C}$, crack growth rate increases sharply due to high $\Delta K$ values, finally leading to catastrophic material failure at $\Delta K_{\mathrm{c}}$. 


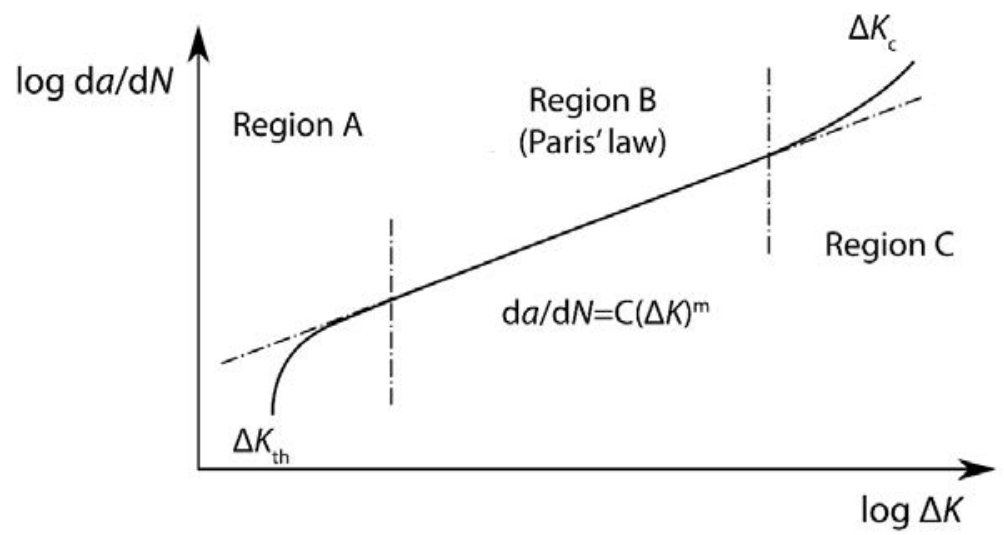

Figure 20. Fatigue crack propagation as commonly seen for most metallic materials.

The growth of short cracks is strongly influenced by local metallurgical features [117]. The short crack propagates until it is decelerated by microstructural barriers like grain boundaries and inclusions which cannot accommodate the initial direction of the crack growth. Hence, surface grain refinement is capable of retarding crack advance at the incipient stage of the fatigue crack propagation. Surface mechanical treatments such as shot peening and deep rolling also contribute to an increased number of microstructural barriers per unit of length as the grains are stretched and elongated by plastic deformation. The compressive residual stresses induced by these processes could further retard and even stop the short crack propagation, thereby resulting in a longer fatigue life.

As a consequence of the crack growth, the stress intensity factor increases and dislocation slips start to take place in different planes in front of the crack tip, which initiates the so-called fatigue striations as a consequence of the blunting and resharpening of the crack tip. Once the fatigue crack propagates into the interior bulk material, surface integrity has less influence, while the propagation behavior and rate are dominated by different combinations of the stress waveform, load frequency, and environment. An increased crack growth rate has been observed for many different materials when fatigued at elevated temperatures, in particular when a dwell time in tension is added [118-122]. This is normally due to either grain boundary embrittlement caused by the environmental attack or fatigue-creep interactions. When the former mechanism is dominant, it is often accompanied by a transition of the failure mode from trans-granular to inter-granular fracture. 



\section{Experimental methods}

In this chapter, the author addresses the experimental work that has been performed in this thesis project. The broaching of Inconel 718 was conducted at Siemens Industrial Turbomachinery $\mathrm{AB}$ in Finspång, Sweden. The shot peeing work on the same alloy was performed at Ytstruktur Arboga AB in Arboga, Sweden, but the samples to be shot-peened have been pre-milled in the workshop at Linköping University. Regarding to another alloy, $\mathrm{AD} 730^{\mathrm{TM}}$, it was machined by turning at Lund University. All other sample preparations, thermal exposure, surface integrity characterization (microstructure, residual stress, micro-hardness, etc.), and fatigue tests were carried out at Linköping University, except for a part of the characterization work using the special methods. For instance, the transmission electron microscopic (TEM) studies, chemical and crystallographic analyses using atom probe tomography (APT) and transmission Kikuchi diffraction (TKD), and the corresponding sample preparations presented in Paper III were performed at Chalmers University of Technology. In addition, the nano-indentation tests presented in Paper I and Paper III were conducted at Lund University. The experimental procedures for the TEM, APT, and TKD work are not described in this chapter, but details can be found in Paper III.

\subsection{Materials}

Inconel 718 alloy used in this work was taken from disc forgings via Siemens Industrial Turbomachinery AB. The chemical composition is given in Table 3 in weight percent. The alloy was solution annealed by the material supplier at $970{ }^{\circ} \mathrm{C}$ for $3.5 \mathrm{~h}$, followed by a two-stage ageing first at $720^{\circ} \mathrm{C}$ for $8 \mathrm{~h}$, further at $620^{\circ} \mathrm{C}$ for 
another $8 \mathrm{~h}$, and then air cooled to room temperature. The $0.2 \%$ yield strength and ultimate strength of the aged forging are $1034 \mathrm{MPa}$ and $1241 \mathrm{MPa}$ at room temperature. $\mathrm{AD} 730^{\mathrm{TM}}$ bars, $75 \mathrm{~mm}$ in diameter and $500 \mathrm{~mm}$ in length, were supplied by Aubert\&Duval. The chemical composition is given in Table 4 . The alloy was solution heat-treated at $1080^{\circ} \mathrm{C}$ for $4 \mathrm{~h}$, and then air cooled to room temperature, followed by an ageing treatment at $730{ }^{\circ} \mathrm{C}$ for $8 \mathrm{~h}$, finally air cooled to room temperature. The heat treatment results in a fine microstructure with a grain size in the range of $\sim 10 \mu \mathrm{m}$. The $0.2 \%$ yield strength and ultimate strength of the aged alloy are $1137 \mathrm{MPa}$ and $1547 \mathrm{MPa}$ at room temperature according to the mechanical tests performed by the material supplier.

Table 3. Chemical composition in $\mathrm{wt} \%$ of Inconel 718 disc forging.

\begin{tabular}{lllllllll}
\hline & $\mathrm{Fe}$ & $\mathrm{Ni}$ & $\mathrm{Cr}$ & $\mathrm{Mo}$ & $\mathrm{Nb}$ & $\mathrm{Ti}$ & $\mathrm{Al}$ & $\mathrm{C}$ \\
\hline Min. (\%) & Bal. & 50 & 17 & 2.8 & 4.75 & 0.65 & 0.2 & \\
Max. (\%) & & 55 & 21 & 3.3 & 5.5 & 1.15 & 0.8 & 0.08 \\
\hline
\end{tabular}

Table 4. Chemical composition in $\mathrm{wt}^{\mathrm{t}} \%$ of the aged $\mathrm{AD} 730^{\mathrm{TM}}$.

\begin{tabular}{cccccccccccc}
\hline $\mathrm{Ni}$ & $\mathrm{Fe}$ & $\mathrm{Cr}$ & $\mathrm{Co}$ & $\mathrm{Mo}$ & $\mathrm{W}$ & $\mathrm{Al}$ & $\mathrm{Ti}$ & $\mathrm{Nb}$ & $\mathrm{B}$ & $\mathrm{C}$ & $\mathrm{Zr}$ \\
\hline Bal. & $3.91-3.96$ & $15.53-15.57$ & 8.42 & 3.02 & 2.59 & 2.32 & 3.51 & 1.12 & 0.01 & 0.01 & 0.034 \\
\hline
\end{tabular}

\subsection{Surface generation \& treatment}

\subsubsection{Broaching}

One of the big interest in this thesis is the broaching of the alloy Inconel 718. A couple of slots were produced by using the linear surface broaching on a vertical broach machine. The broaching process used in the present project is similar to that typically used for manufacturing fir-tree root fixings in the turbine disc production at Siemens Industrial Turbomachinery AB. The broach is made of PM-T15 high speed steel (65-67 HRC) under semi-worn conditions with a rake angle of $12^{\circ}$, clearance angle of $3^{\circ}$, and rise-per-tooth of $0.066 \mathrm{~mm}, 0.054$ to $0.038 \mathrm{~mm}$, and 0.013 $\mathrm{mm}$ for roughing, semi-finishing, and finishing sections. The semi-worn condition is defined from the industrial point of view as that the broach has been used for several broaching of discs, while it can still keep the required dimension tolerance. The cutting speed was constant at $3 \mathrm{~m} / \mathrm{min}$, and the broaching oil as cooling lubricant was applied throughout the entire broaching operations. 


\subsubsection{Shot peening}

Shot peening of Inconel 718 is another subject of interest in this thesis. A set of rectangular bars were cut out, and the surface that is to be shot-peened was premachined by face milling using a $20 \mathrm{~mm}$ diameter cutter with two uncoated cemented carbide inserts. The cutting speed was fixed at $30 \mathrm{~m} / \mathrm{min}$ (corresponding spindle speed was $382 \mathrm{rpm}$ ) and the depth of cut was $0.5 \mathrm{~mm}$. The feed direction was along the longitudinal direction of the bars with a feed rate of $76 \mathrm{~mm} / \mathrm{min}$, while no coolant was applied. The shot peening was carried out on the pre-milled surfaces using spherical S170 H cast steel shots with 150 to 200\% surface coverage. The shotpeening intensity was varied in the range of 0.2 to $0.3 \mathrm{mmA}$ (Almen intensity). Some of the shot-peened bars were heat treated in a furnace with atmospheric environment in order to produce thermally-exposed specimens for studies of thermal stress relaxation and also for four-point bending fatigue tests.

\subsubsection{Wire electrical discharge machining.}

Wire electrical discharge machining was performed on the aged Inconel 718 using a commercial FANUC wire EDM cutting machine with a brass electrode that has a diameter of $0.25 \mathrm{~mm}$ under a dielectric fluid. The cutting process was conducted at a working voltage of 43-46 V, a working current of 6.5-6.6 A, a pulse-on duration of $10 \mu \mathrm{s}$, and a feed speed of $3.32-3.35 \mathrm{~mm} / \mathrm{min}$.

\subsubsection{Turning}

Continuous longitudinal turning was conducted on the aged bars of AD $730^{\mathrm{TM}}$ with uncoated PCBN inserts SECOMAX ${ }^{\mathrm{TM}} \mathrm{CBN} 170$ (65\% cBN by volume, $2 \mu \mathrm{m}$ grain size, and $\mathrm{TiCN}$ binder), reinforced by $\mathrm{SiC}$ whisker fibers. The inserts were manufactured with a honed cutting edge and an edge radius of $25 \mu \mathrm{m}$. The turning operations were performed on a SMT500 CNC turning center. The insert was mounted in the tool holder PCLNL2525M12 JETL with a rake angle of $-6^{\circ}$ and clearance angle of $-6^{\circ}$. A series of cutting speeds, $V_{c}=150,200,250$, and $300 \mathrm{~m} / \mathrm{min}$, and feed rate, $f=0.1,0.15$, and $0.2 \mathrm{~mm} / \mathrm{rev}$ was applied. The depth of cut was constant, $a_{p}=0.25 \mathrm{~mm}$, and coolant was applied at $18 \mathrm{bar}$. 


\subsection{Surface integrity characterization}

\subsubsection{Scanning electron microscopy}

Substantial microstructural characterization has been carried out on the basis of scanning electron microscope (SEM) in this thesis. In some cases, a target surface was directly inserted into the SEM in order to characterize the surface morphology. However, it is more common that the surface was cross-sectioned, ground, and mechanically polished for cross-sectional observation by using a Struer grinding and polishing machine. SiC grinding papers were used from \#500 with a particle size of $30 \mu \mathrm{m}$ down to \#4000 with a particle size of $5 \mu \mathrm{m}$ before the mechanical polishing with diamond suspensions from $3 \mu \mathrm{m}$ to $1 / 4 \mu \mathrm{m}$. Chemical polishing was performed as the last step for good contrast SEM images. After each step, specimens were cleaned by water and ethanol, and ultrasonic cleaning was also conducted to remove contaminations from either the grinding paper or the polishing agent. Three SEM related techniques were used for the microstructural studies: these are electron channeling imaging (ECCI), electron backscatter diffraction (EBSD), and energy dispersive spectroscopy (EDS).

In 1967, Coates [123] observed strong crystallographic orientation dependence of the intensity of the primary backscattered electrons (BSEs). Immediately following this, Booker et al. [124] confirmed Coates' findings and put forward a theoretical interpretation of this phenomenon: the intensity of the BSEs changes rapidly with orientations when the incident beam is close to the Bragg condition for a given set of lattice planes. In this paper, they also suggested a basic idea of using the electron channeling phenomenon to image dislocations or other metallurgical defects near the surface of a bulk material. When the incident beam is oriented at the Bragg positon $\left(\theta_{\mathrm{B}}\right)$ for the given set of crystal planes, the local distortion of the lattice planes when dislocations exist will provide a sufficient contrast in the SEM image, as illustrated in Fig. 21. The ECCI technique has been successfully used to capture plastic deformation, twin structures, and even dislocations in highly deformed materials [125-128]. Fig. 22 shows the observations beneath the surface of broached Inconel 718 , using the ECCI technique, where sheared and plastically deformed grains can be clearly identified.

EBSD is a microstructural-crystallographic technique that can be used to identify the crystal structure of a material, and to index its crystallographic orientation, by using Kikuchi patterns [129]. EBSD mapping provides an efficient approach to view plastic deformation at both macrostructural and microstructural levels by monitoring the extent to which the quality of the Kikuchi patterns has been changed [130] or by calculating intra-granular crystal misorientations [131,132]. EDS is an analytical technique widely used for the element analysis and chemical composition 
quantification of a material [133]. When combined with EBSD, it can be used to identify the precipitates formed in alloys $[11,134]$.

In this thesis, a majority of the microstructural investigations were performed with a Hitachi SU-70 field emission gun (FEG)-scanning electron microscope which is equipped with a 4-quadrant solid state BSE detector, an OXFORD EBSD detector, and an energy-dispersive detector. The EBSD data analysis, for instance, the intragranular crystal misorientation calculation, was done by using the HKL software CHANEL 5 combined with MATLAB ${ }^{\circledR}$.
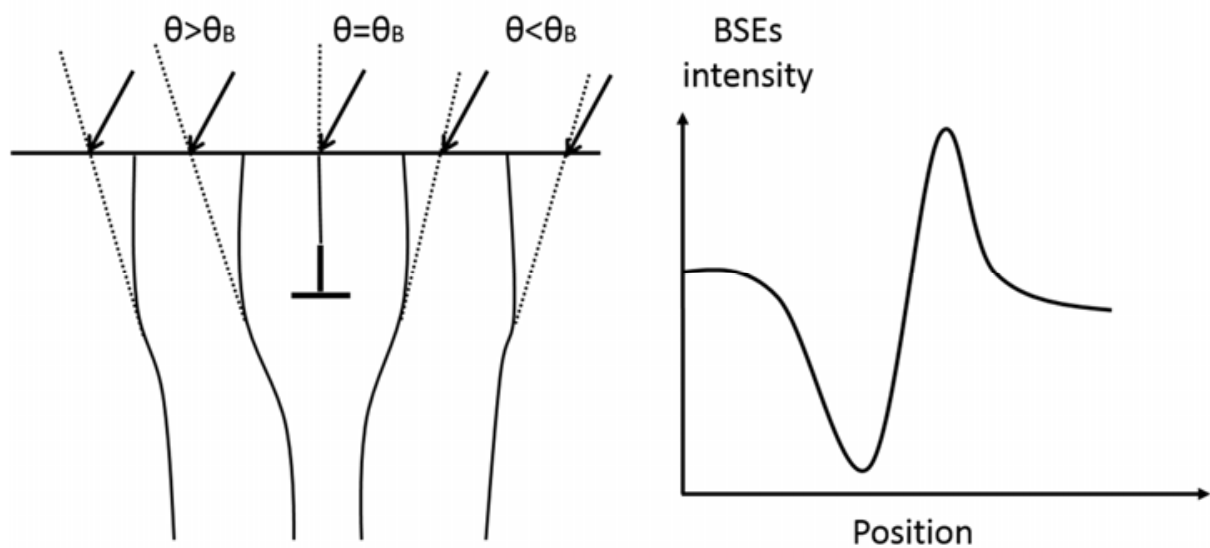

Figure 21. Schematic illustration showing how the local distortion near a dislocation gives rise to an alteration of the BSE intensity which allows the dislocation to be imaged.
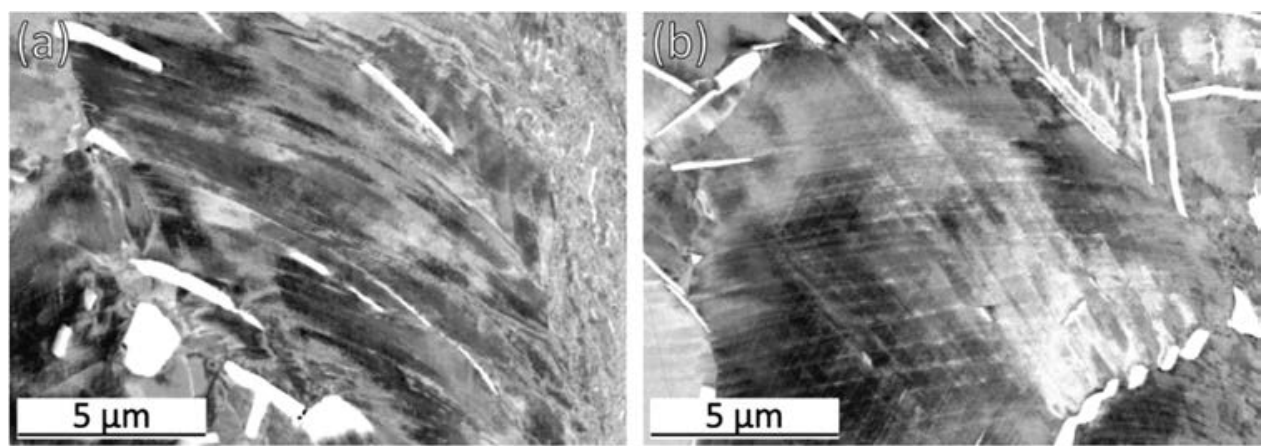

Figure 22. ECCI micrographs clearly showing the deformation features beneath the surface of broached Inconel 718: (a) shearing deformation and (b) slip bands. 


\subsubsection{Micro-hardness tests \& Nano-indentation}

Work hardening in relation to the intensive plastic deformation occurring during machining or surface treatments like shot peening is an aspect of importance when evaluating the surface integrity. Meanwhile, the surface work hardening could be released at high temperatures because of the thermal softening effect. In order to obtain the distribution of hardness against depth for a target surface, Vickers microhardness tests were carried out on the polished cross-section of the specimen at varying depths from the surface. The load that used for the tests was $100 \mathrm{~g}$ with a holding time of $10 \mathrm{~s}$, and most of the measurements started at 20-30 $\mu \mathrm{m}$ away from the edge of the cross section, i.e., the top surface, in order to minimize the edge effect.

Nano-indentation was developed in the early 1970s [135,136], and has become an increasingly popular test method for mechanical properties of small volumes of a material, particularly in the area of thin films [137-139]. It is different from a microhardness measurement as small loads and tip size are used, resulting in an indent with only a few square micrometers or even nanometers. An indenter with a geometry known to high precision is employed in nano-indentation. When the indenter is pressed into a specimen with a given maximum load, a record of the penetration depth during loading and un-loading is made synchronously. The area of the indent then can be calculated by using the known geometry of the indenter, and the hardness and Young's modulus of the specimen can be analyzed form the load-displacement curve based on the Oliver and Pharr method [140].

Nano-indentation had wide applications in this thesis work, in particular when measuring the hardness of a superficial layer. For instance, in Paper I, the in-depth hardness as close as $5 \mu \mathrm{m}$ away from the broached surface was successfully measured on the cross-section by nano-indentation. Another successful example was to measure the hardness and Young's modulus of the broached white layer from the top of the broached surface, see Paper III. All nano-indentation tests were conducted under load control mode on the NanoTest Vantage system with a loading range of 0.01 to $500 \mathrm{mN}$. A Berkovich diamond indenter with a tip radius of $120 \mathrm{~nm}$ was used in the tests. The load level was set to be $20-50 \mathrm{mN}$ depending on the specific case with a loading rate of $5 \mathrm{mN} / \mathrm{s}$ and a hold time of $30 \mathrm{~s}$.

\subsubsection{Residual stress measurements}

Residual stresses in a component are commonly measured by either monitoring component distortions when deliberately removing material to allow the stresses to relax, or by diffraction methods. Laboratory X-ray diffraction, synchrotron (hard Xray) diffraction and neutron diffraction as the most widely used diffraction methods for residual stress measurement are based on the same principle and they are 
complementary to each other $[74,75]$. Laboratory $\mathrm{X}$-rays can only be used for the measurement of surface residual stresses since most X-rays are absorbed after penetrating less than $100 \mu \mathrm{m}$ in materials owing to the electromagnetic interaction with orbiting electrons. In contrast, the weak interaction of the uncharged neutrons with electrons allows the neutron beam to penetrate even a few hundred millimeters into some light metals, the penetration depth approaches $200 \mathrm{~mm}$ in the case of $\mathrm{Al}$, for instance, with a result that bulk residual stresses can be measured. Synchrotron $\mathrm{X}$-rays whose intensity can be as much as a million times of that of the laboratory $\mathrm{X}$ rays also provide over a thousand times more penetration depth in metals. However, the disadvantages of the neutron and synchrotron diffraction are the high cost and the low lateral spatial resolution.

The residual stress measurements in this thesis were made by using $\mathrm{X}$-ray diffraction in a four-circle Seifert X-ray diffractometer. $\mathrm{Cr}-\mathrm{K} \alpha$ radiation was chosen, giving a high diffraction peak at $20 \sim 128^{\circ}$ for the $\{220\}$ family of lattice planes of the nickelbased matrix. Peaks were measured at nine $\psi$-angles between $\psi=+55^{\circ}$ and $\psi=-55^{\circ}$ (or between $\psi=+45^{\circ}$ and $\psi=-45^{\circ}$ depending on the sample geometry). Pseudo Voigt function was used for peak fitting in order to determine the diffraction peak position and the Full Width at Half Maximum (FWHM, i.e. peak broadening). Residual stresses were calculated based on the " $\sin ^{2} \psi$ " method with an X-ray elastic constant of $4.65 \times 10^{-6} \mathrm{MPa}^{-1}$ for Inconel 718 and $5.59 \times 10^{-6} \mathrm{MPa}^{-1}$ for AD $730^{\mathrm{TM}}$. Details with respect to the principle of the " $\sin ^{2} \psi$ " method has been addressed both in the previous Licentiate thesis [5] and in [141]. The in-depth profiles of residual stresses were obtained by layer removal using electrolytic polishing with Struers LectroPol-5. The deviation of the measured values due to stress relaxation of the layer removal were corrected in the case that the measured component is assumed to be a flat plate.

\subsection{Four-point bending fatigue}

Four-point bending is a surface sensitive test method of fatigue since the specimen has a flat surface of interest on which a uniform tensile stress is applied and meanwhile a stress gradient is created in depth. The specimens were tested at room temperature under load control using a sinusoidal waveform at a load ratio of $\mathrm{R}=0.1$ and a frequency of $20 \mathrm{~Hz}$. Two different types of sample geometry were used: rectangular bars with a sharp edge, e.g., in Paper II and VII, and rectangular bars with a chamfered corner on the tensile side, e.g., in Paper V and VI; they are also illustrated in Fig. 23. The test bars were prepared with a general dimension of $10 \times 10 \times 80 \mathrm{~mm}^{3}$, while the distance between the two loading and two supporting rollers was $12 \mathrm{~mm}$ and $60 \mathrm{~mm}$, respectively. This sample size and test apparatus can 
provide uniform stress distribution on the tensile surface between the two loading rollers [142]. When testing the bars with a sharp edge, fatigue cracks may initiate from the corner on the tensile side, whereas this risk is annihilated if the corner has been chamfered; which one to use depends on the purpose of the specific study.

As reviewed in Chapter 6, a major effect of surface integrity on fatigue is to alter the crack initiation behavior as fatigue cracks are normally formed at a surface. All specimens were fatigued until rupture or run out at $10^{7}$ cycles. The specimen deflection at the maximum and minimum load versus the number of cycles was recorded, and a line was fitted to the initial linear part of the deflection rang-number of cycles curve and extrapolated into the larger cycle region. The fatigue life was defined as the number of cycles corresponding to $1 \%$ increase of the deflection range from the fitted line, instead of the number of cycles to rupture. With such failure criteria, the effect of surface integrity was highlighted as the specimen lifetime was largely dominated by the fatigue cycles spent on crack initiation. The failed specimens were examined under SEM in order to identify the preferential sites where fatigue cracks may initiate.
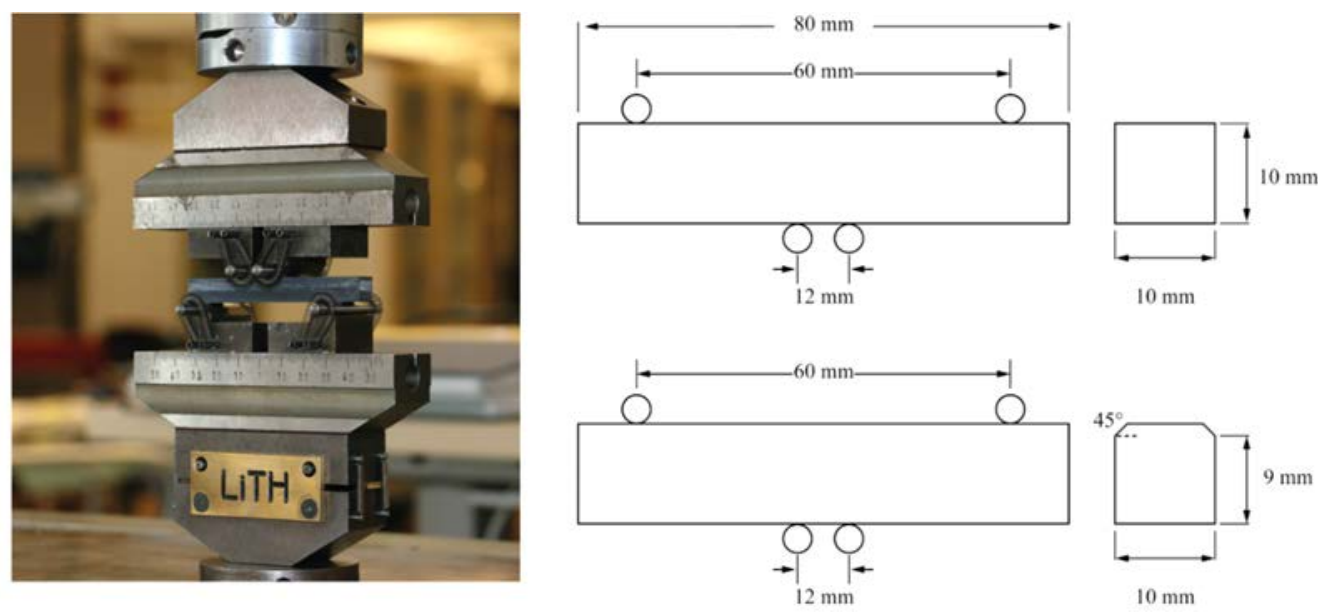

Figure 23. Four-point bending fatigue setup and test bars with two different geometries. 


\section{Review of papers included}

\section{Broaching related}

\section{Paper I}

Surface integrity and structural stability of broached Inconel 718 at high temperatures

As described in Section 4.1.2, broaching is one of the last manufacturing steps in turbine disc production which generates profiled slots on the rim of the disc for blade mounting. These broached blade root fixings normally represent the most critical regions from the point of view of fatigue failure. Accordingly, in this first paper, the surface integrity changes in Inconel 718 associated with the broaching process were systematically examined, and the surface structural stability of the broached alloy at elevated temperatures, in terms of microstructural evolution and residual stress relaxation, has also been addressed. All surface integrity studies, for both as-broached and thermally-exposed samples, were performed on the flank surface of the second tooth of the broached fir-tree slots, on which turbine blades are in intimate contact with the disc due to large centripetal forces. The typical service temperature for an Inconel 718 turbine disc is covered in the chosen temperature range of this study $\left(450-650^{\circ} \mathrm{C}\right)$.

Surface cavities and debris dragging, sub-surface cracks, high intensity of plastic deformation, and generation of tensile residual stresses were identified as the main surface integrity issues in broached Inconel 718. Most of the surface cavities and sub-surface cracks were found to be associated with the cracking and breakage of carbide particles in the surface and sub-surface microstructure. The plucking of the 
cracked carbides and their re-deposition on the machined surface caused surface dragging during the next pass of the cutting edge.

There is a significant thermal impact during broaching as evident by the white layer formation and surface tension despite the low cutting speed of $3 \mathrm{~m} / \mathrm{min}$ as well as the use of coolant. At the relatively high temperatures of $550{ }^{\circ} \mathrm{C}$ and $650{ }^{\circ} \mathrm{C}$, the surface white layer underwent recrystallization, and therefore the surface tensile residual stresses were completely relaxed in a short time. However, great relaxation of the sub-surface tensile layer was only observed at $650{ }^{\circ} \mathrm{C}$, whereas at such high temperature, coarsening of the $\gamma^{\prime \prime}$ occurred. Our findings suggest that for Inconel 718 , if tensile residual stresses are induced during machining, they are difficult to be removed by subsequent stress relief annealing, or during the service at elevated temperatures which do not induce extensive surface recrystallization. Surface treatment, such as shot peening, which can introduce beneficial compressive residual stresses, might be necessary if a high fatigue resistance is required.

Another primary finding of this study is the $\alpha$-Cr precipitation, as a form of microstructural degradation in Inconel 718 , took place beneath the broached surface for all temperatures investigated, $450{ }^{\circ} \mathrm{C}, 550{ }^{\circ} \mathrm{C}$, and $650{ }^{\circ} \mathrm{C}$. This was facilitated by the plastic deformation induced by broaching which contributes to faster $\mathrm{Cr}$ diffusion in the matrix and an enhanced tendency of the $\delta$ precipitation.

\section{Paper II}

On the conjoint influence of broaching and heat treatment on bending fatigue behavior of Inconel 718

As a continuation to the work presented in Paper I, the fatigue life and corresponding crack initiation behavior of broached Inconel 718, both asmanufactured and thermally-exposed samples $\left(550^{\circ} \mathrm{C}\right.$ and $\left.650^{\circ} \mathrm{C}\right)$, have been investigated and correlated with the effect of their surface integrity. The fatigue test bars were taken from the flat bottom of the broached fir-tree slots, not the contact surface of the second tooth where the characterization was carried out in Paper I, due to the large sample geometry. At the part where the fatigue samples were extracted, compressive residual stresses were generated instead of the surface tension as observed previously on the contact surface in Paper I. This is an interesting finding showing that the broaching process produced an anisotropic residual stress distribution over the surface of the broached slot. In order to make a comparison, fatigue samples with a polished surface were also prepared and subjected to the same thermal exposure as that performed on the broached ones. 
The broaching process increased the fatigue life of the alloy compared with the samples prepared by polishing. Two distinctly different crack initiation mechanisms were observed. The development of fatigue damage in the as-polished samples was dominated by surface crack initiation associated with local slip activities. In the asbroached samples, sub-surface crack initiation occurred even that a large number of defects were created on the broached surface. The fatigue crack initiation from these flaws was retarded by the surface compression, which resulted in a longer lifetime.

Generally, a detrimental effect concerning the fatigue life of the alloy was found when a heat treatment was introduced prior to the fatigue test. The polished samples with $300 \mathrm{~h}$ heat treatment at $650^{\circ} \mathrm{C}$ was an exception where an increased fatigue life was obtained, most likely owing to the increased ductility of the alloy. Instead of the local deformation, oxidized surface carbides turned out to be the preferential sites where fatigue cracks may initiate for the heat-treated samples with a polished surface. The detrimental effect of heat treatment on the fatigue life was more predominant for the broached samples, especially at $650{ }^{\circ} \mathrm{C}$. This is due to the great thermal relaxation of the compressive residual stresses on the broached surface. Fatigue cracks were initiated at the surface from the defects produced by broaching, oxidized carbides, and those micro-notches formed due to the inter-granular oxidation during heat treatment. The inter-granular weakening took place due to the large amount of grain boundaries in the recrystallized surface layer acting as fast diffusion channels, and therefore the oxidation could proceed downwards inter-granularly.

\section{Paper III}

Nano-scale characterization of white layer in broached Inconel 718

In Paper I, it was clear that a surface white layer was formed during the broaching of Inconel 718 even if coolant was applied and the broaching was performed under a relatively low strain rate at a cutting speed as low as $3 \mathrm{~m} / \mathrm{min}$. The presence of a white layer is certainly unfavorable, as described in Section 5.2, because it eases fatigue crack initiation and therefore impairs the resistance of the disc to fatigue failure. Greater insights to the microstructural characteristics and mechanical properties of broached white layers are of significance if lifetime estimation is to be accurate for broached components. More importantly, a deep understanding is needed of the mechanism controlling the white layer formation during broaching in order to annihilate it on the broached parts. In Paper III, examinations using multiple advanced characterization techniques with nano-scale resolution were performed on the surface white layer formed when broaching the alloy 


\section{Inconel 718, by which the microstructural evolution within the white layer and the mechanical properties of this layer have been comprehensively studied.}

The observations under transmission electron microscope (TEM) showed that the broached white layer consists of nano-sized grains, mostly in the range of $20 \mathrm{~nm}$ to $50 \mathrm{~nm}$. The crystallographic texture detected by transmission Kikuchi diffraction (TKD) further suggested that strong shear deformation is the main cause of the refined microstructure of this surface layer. By using atom probe tomography (APT), co-located $\mathrm{Al}$-rich and $\mathrm{Nb}$-rich fine clusters were identified, which are most likely to be $\gamma^{\prime}$ and $\gamma^{\prime \prime}$ clusters in a form of co-precipitates. The clusters showed elongated and aligned appearance in relation to the severe shearing history of the surface microstructure. With these microstructural and crystallographic features, it can be concluded that the formation of the surface white layer was essentially caused by adiabatic shear localization in which the dominant metallurgical process is rotational dynamic recrystallization based on mechanically-driven subgrain rotations.

The distinct mechanical properties of the broached white layer from that of the bulk material was successfully captured by nano-indentation. The grain refinement within the white layer enhanced the surface nano-hardness by $14 \%$, but caused a reduction almost up to $10 \%$ in elastic modulus, compared to that of the bulk material. This can be rationalized by the greatly increased volume fraction of grain boundaries when the grain size was reduced down to the nanoscale. 


\section{Shot-peening related}

\section{Paper IV}

Residual stress and thermal relaxation of shot-peened Inconel 718 nickel-based superalloys

As evident from Paper II, if compressive residual stresses are present on a machined surface, it benefits fatigue performance. Although surface compression is occasionally formed when machining nickel-based superalloys, as the case shown in Paper II for example, the generation of tensile residual stresses is more often taking place due to the poor machinability of these alloys. Shot peening has beneficial effects on fatigue resistance by introducing compressive residual stresses in the shotpeened layer. However, these benefits are retained in service only if the surface compression remains stable during mechanical loading or at elevated temperatures.

In Paper IV, the surface residual stress generated by shot peening and the thermal relaxation behavior have been investigated in Inconel 718. The underlying mechanism of the stress relaxation was further interpreted by both analytical model and surface microstructural studies.

Shot peening was carried out on a set of pre-milled samples with surface tensile residual stresses. After the shot peening, the surface tension induced by machining was annihilated, while a high compressive residual stress was created on the shotpeened surface. The fatigue performance of these two groups of samples with different surface integrity was tested and the results are shown in Paper V.

When exposed at elevated temperatures, both the surface residual stress and workhardening induced by shot peening was reduced. The relaxation behavior and corresponding mechanism showed strong temperature dependence. The relaxation of the surface work-hardening turned out to be primarily a thermally activated process that can be described by the Zener-Wert-Avrami function, however, there existed a transition of the dominant mechanism from thermal recovery to recrystallization as the temperature was increased to $550{ }^{\circ} \mathrm{C}$ and above. At the relatively low temperature of $450^{\circ} \mathrm{C}$, the stress relaxation on the shot-peened surface was dominated by thermal recovery. However, the surface compression was completely relaxed at $500{ }^{\circ} \mathrm{C}, 550^{\circ} \mathrm{C}$, and $600{ }^{\circ} \mathrm{C}$ within a short period of time, and the Zener-Wert-Avrami function was found not to be adoptable. It suggests that the stress relaxation on the shot-peened surface appears to be a complex process, which is not simply controlled by the thermally activated mechanisms. It could also be influenced by other mechanisms, such as $\alpha-\mathrm{Cr}$ precipitation and material yielding. 


\section{Paper V}

Effect of cooling and shot peening on residual stresses and fatigue performance of milled Inconel 718

The use of coolant is normally an effective way of reducing the tensile residual stresses generated on a machined surface, and meanwhile, as shown in Paper IV, high compressive residual stresses can be further induced despite the machining history by using post-machining surface treatment of shot peening. The corresponding fatigue life as influenced by these changes of surface integrity remains to be a research question which has been addressed in Paper V.

It was found that tensile residual stresses were created on the milled surface, regardless of the use of coolant, however, it is clear that the wet milling operation led to a lower surface tension and a reduced thickness of the tensile layer. The shot peening performed on the dry-milled specimens completely annihilated the surface tensile residual tresses and introduced a high level of surface compression. A comparable fatigue life was obtained for the milled specimens with or without the use of coolant. This is very likely attributed to that the milling-induced surface damage with respect to cracked carbides and nitrides is the predominant cause of the fatigue failure. The presence of the compressive layer induced by shot peening resulted in a significant increase of the fatigue life and strength as it retarded surface cracking from the pre-existing cracked non-metallic inclusions and shifted the crack initiation sites to sub-surface regions. However, the extent to which the lifetime was prolonged was decreased as the applied load was increased due to the residual stress relaxation in low cycle fatigue resulting from significant cycling strains.

\section{Paper VI}

Effect of thermal exposure on fatigue performance of shot-peened Inconel 718

The beneficial effects of shot peening may diminish for high temperature applications since the thermal impact causes relaxation of the compressive residual stresses, as seen in Paper IV. It is a significant concern for shot-peened turbine components as they mostly operate at elevated temperatures.

In Paper VI, the effect of thermal exposure on the fatigue performance of shotpeened Inconel 718 was assessed. The thermal exposure was performed at two temperatures, $450^{\circ} \mathrm{C}$ and $600{ }^{\circ} \mathrm{C}$, which covers the typical temperature range for turbine disc applications. 
It was found that the beneficial effect of shot peening in fatigue life extension still remained in the thermally-exposed specimens, but was reduced by thermal exposure as it led to relaxation of the compressive residual stresses in the shot-peened layer. The extent to which the fatigue life was decreased showed good correspondence with the amplitude of the stress relaxation in the thermally-exposed specimens depending on the temperature and exposure time. As a consequence of the stress relaxation on the shot-peened surface, the fatigue failure of the thermally-exposed specimens was dominated by surface crack initiation. The oxidized niobium carbides and delaminated surface structure associated with shot indentations have been identified as the preferential sites where fatigue cracks may initiate. The oxidized surface carbides were further found to become the dominant initiation sites for fatigue cracks in the specimens exposed at $600{ }^{\circ} \mathrm{C}$.

\section{Other subjects}

\section{Paper VII}

Surface integrity and fatigue performance of Inconel 718 in wire electrical discharge machining

Wire electrical discharge machining (WEDM) has been considered to be a good candidate of manufacturing technology to the traditional broaching operation for the production of fir-tree slots on turbine discs. As introduced in Section 4.2, it cuts materials regardless of their hardness or strength, and little plastic deformation is induced beneath the machined surface. However, the giant heat generated during the process usually causes the generation of a surface recast layer or a surface white layer. In Paper VII, the characteristic features of the surface recast layer formed in wire electrical discharge machining of Inconel 718 were examined, and the effect of this layer on the fatigue performance of the alloy, in particular its effect on fatigue crack initiation, was also investigated.

The specimens machined by WEDM showed a noticeable decrease, approximately by $25 \%$, in fatigue life compared to those specimens with a polished surface. Examinations of the fracture surface indicated that the presence of the surface recast layer facilitated the crack initiation when subjected to fatigue. Instead of one primary crack initiation site in the case of the polished specimens, there are multiple crack origins at the EDM cut surface. The reason is that the surface recast layer consists of vast potential sites for fatigue crack formation. It was found that the fatigue cracks were initiated at surface craters or the pre-existing defects in the recast layer, such as micro-cracks and micro-voids. The surface irregularities, high propensity of the 
recast layer to cracking, together with the large surface tensile residual stresses are proposed to be responsible for the loss in fatigue life in the EDM cut specimens.

\section{Paper VIII}

Effect of cutting conditions on machinability of $\mathrm{AD} 730^{\mathrm{TM}}$ during high speed turning with PCBN tools

AD $730^{\mathrm{TM}}$ is a novel wrought nickel-based superalloy for high-temperature turbine disc applications. Studies on the machinability of the alloy and suitable machining parameters are of great importance for cost effective machining and desired service performance. In Paper VIII, the machinability of the new alloy AD $730^{\mathrm{TM}}$ was evaluated in terms of cutting force and surface integrity at different cutting speeds and feed rates during high speed turning with uncoated polycrystalline cubic boron nitride (PCBN) tools. Four cutting speeds, $V_{c}=150,200,250$, and $300 \mathrm{~m} / \mathrm{min}$, were selected with a constant feed rate of $f=0.2 \mathrm{~mm} / \mathrm{rev}$, while for the highest cutting speed of $300 \mathrm{~m} / \mathrm{min}$, two additional feed rates, 0.1 and $0.15 \mathrm{~mm} / \mathrm{rev}$, were also applied. The depth of cut was constant at $a_{p}=0.25 \mathrm{~mm}$. The PCBN tools were used in new conditions.

The results showed that increasing the cutting speed from $150 \mathrm{~m} / \mathrm{min}$ to $200 \mathrm{~m} / \mathrm{min}$ benefits the machining of the alloy as all cutting force components decrease due to the increased cutting temperature. At both two cutting speeds, the turning operations resulted in little plastic deformation in the surface and sub-surface microstructure. However, as a further increase of the cutting speed to $250 \mathrm{~m} / \mathrm{min}$ and above, it showed an increase of the cutting force and feed force which is most likely due to rapid tool wear. The plastic deformation beneath the machined surface became much stronger and more adiabatic at such high cutting speeds. This is in particular the case at $300 \mathrm{~m} / \mathrm{min}$, where a continuous white layer was formed on the machined surface. As for the effect of feed rate, increasing the feed rate resulted in higher cutting forces, and thereby led to greater plastic deformation and stronger thermal impacts.

The surface residual stresses induced during turning of $\mathrm{AD} 730^{\mathrm{TM}}$ have been found to be tensile regardless of the cutting conditions applied. Either increasing the cutting speed or feed rate increases the surface tension as they can exacerbate the thermally induced deformation on the machined surface. However, it seems that the feed rate has a slightly less effect as compared to the cutting speed. 


\section{9}

\section{Conclusions}

Due to increased demand for more efficient and flexible land-based gas turbines, fatigue resistance of turbine components needs to be improved. The focus of this thesis work is on the effect of surface integrity on fatigue behavior and performance of nickel-based superalloys. The ultimate goal is to improve the fatigue properties by surface enhancement through process optimization of machining or post-machining surface treatments such as shot peening.

To reach this goal, a number of studies have been carried out. The results show that machining processes can cause changes of surface integrity, particularly when machining nickel-based superalloys due to their poor machinability. Surface irregularity and defects, in the form of e.g., micro-voids, micro-cracks, or cracked non-metallic inclusions, induced by machining provide weak sites where fatigue cracks are preferably initiated, and, therefore, are in general detrimental to the fatigue performance. This effect can be further facilitated if tensile residual stresses are present on the machined surface. On a contrary, if compressive residual stresses are induced during machining, the surface crack initiation is retarded, which can lead to an enhanced fatigue life.

Shot peening is found to be an effective post-machining surface treatment, by which the fatigue performance of a machined component can be greatly improved since high compressive residual stresses are induced on the shot-peened surface, regardless of the machining history.

For high temperature applications, the thermal impacts generally deteriorate the surface integrity and therefore also the fatigue performance. A reduced fatigue life is often obtained if thermal exposure has been made prior to the test. Oxidation is inevitable at elevated temperatures. A high tendency of fatigue crack initiation at 
surface oxidized particles, e.g., the oxidized carbides in the case of the Inconel 718, has been observed. Moreover, either machining or shot peening cause great plastic deformation in the surface and sub-surface microstructure. The deformed microstructure is not stable when subjected to thermal exposure. Recrystallization, precipitation of undesired particles, and oxidation along grain boundaries of the recrystallized grains can take place depending on the temperature and exposure time applied. The high temperatures even cause thermal relaxation of the beneficial compressive residual stresses. This is particularly a concern for high temperature applications of shot-peened components.

The findings from this thesis work showed the importance of understanding surface integrity effects for fatigue applications, especially in harsh environments. This benefits fatigue failure analyses of gas turbine components. More importantly, the knowledge gained in the work could be used for surface enhancement of those turbine components which are subjected to a high risk of fatigue failure, and therefore contributes to more efficient and flexible power generation by gas turbines. 


\section{Outlook}

This thesis work increases a number of interest for further research in the future:

1. Some aspects of surface integrity has been found to be critical for component resistance to fatigue, such as surface defect and residual stress. How to optimize these surface integrity changes in machining by applying suitable cutting parameters is of great interest for industrial production processes.

2. Surface microstructural changes associated with the plastic deformation induced by machining are commonly observed at elevated temperatures, such as recrystallization and precipitation. Although some work has been performed in this Ph.D. thesis, more investigations are needed to better interpret these surface microstructural evolution, their mechanisms, and the effect on surface mechanical properties. This is particularly important for high temperature applications.

3. Another interesting topic is how to stabilize the surface compressive residual stresses induced by shot peening at elevated temperatures, and thereby maintain their beneficial effects on retardation of surface crack initiation for high temperature fatigue applications. One way is to optimize the shot peening process with an overall aim of reducing the amount of plastic deformation in the shot-peened layer, but still keeping the surface compression strong enough to retard the surface crack initiation during fatigue.

4. Laser peening is an advanced technique for post-machining surface treatment. Studies with regard to its effect on fatigue properties of nickel-based superalloys, in particular at elevated temperatures, are of interest as well. 
5. Continuous investigations on the machinability, surface integrity, and fatigue performance of the new alloy $\mathrm{AD} 730^{\mathrm{TM}}$ will provide more knowledge that benefits its application in high-efficient gas turbines.

6. As always, it would be extremely interesting to compare the findings presented in this Ph.D. thesis based on the experimental work in the laboratory with the observations in those service-exposed turbine components. Where fatigue cracks are preferably initiated in real life? 


\section{Bibliography}

[1] R.C. Reed, The Superalloys: Fundamentals and Applications, Cambridge University Press, 2006.

[2] S.R. Lampman, ASM Handbook: Volume 19, Fatigue and Fracture, ASM International. (1996).

[3] R. McClung, A literature survey on the stability and significance of residual stresses during fatigue, Fatigue Fract. Eng. Mater. Struct. 30 (2007) 173-205.

[4] A. Devaux, L. Berglin, L. Thebaud, R. Delattre, C. Crozet, O. Nodin, Mechanical properties and development of supersolvus heat treated new nickel base superalloy AD730 ${ }^{\mathrm{TM}}$, MATEC Web of Conferences. 14 (2014) 01004.

[5] Z. Chen, Surface Integrity of Broached Inconel 718 and Influence of Thermal Exposure, Linköping University Electronic Press, 2014.

[6] T.J. Carter, Common failures in gas turbine blades, Eng. Failure Anal. 12 (2005) 237-247.

[7] B. Cowles, High cycle fatigue in aircraft gas turbines-an industry perspective, Int. J. Fract. 80 (1989) 147-163.

[8] Z. Mazur, A. Luna-Ramirez, J. Juárez-Islas, A. Campos-Amezcua, Failure analysis of a gas turbine blade made of Inconel 738LC alloy, Eng. Failure Anal. 12 (2005) 474-486.

[9] L. Witek, Failure analysis of turbine disc of an aero engine, Eng. Failure Anal. 13 (2006) 9-17.

[10] J. Saarimäki, Effect of Dwell-Times on Crack Propagation in Superalloys, Linköping University Electronic Press, 2015. 
[11] Z. Chen, R.L. Peng, J. Moverare, P. Avdovic, J. Zhou, S. Johansson, Surface integrity and structural stability of broached Inconel 718 at high temperatures, Metall. Mater. Trans. A 47 (2016) 3664-3676.

[12] G. Sabol, R. Stickler, Microstructure of nickel-based superalloys, Phys. Status Solidi b. 35 (1969) 11-52.

[13] E.W. Ross, C.T. Sims, Nickel-base alloys, Wiley-Interscience, John Wiley and Sons, Superalloys II-High Temperature Materials for Aerospace and Industrial Power, (1987) 97-133.

[14] R. Eriksson, Thermal Barrier Coatings: Durability Assessment and Life Prediction, Linköping University Electronic Press, 2013.

[15] J.R. Davis, Nickel, Cobalt, and their Alloys, ASM international, 2000.

[16] D. Paulonis, J. Oblak, D. Duvall, Precipitation in nickel-base alloy 718, Trans. Quart. ASM. 62 (1969) 611-622.

[17] J.M. Oblak, D.F. Paulonis, D.S. Duvall, Coherency strengthening in Ni-base alloys hardened by DO22 gamma double prime precipitates, Metall.Trans. 5 (1974) 143-153.

[18] A. Oradei-Basile, J.F. Radavich, A current T'T'T diagram for wrought alloy 718, Superalloys. 718 (1991) 325-335.

[19] A. Devaux, B. Picqué, M. Gervais, E. Georges, T. Poulain, P. Héritier, AD730 ${ }^{\mathrm{TM}}$-a new nickel-based superalloy for high temperature engine rotative parts, Superalloys 2012. (2012) 911-919.

[20] A. Devaux, E. Georges, P. Héritier, Development of new C\&W superalloys for high temperature disk applications, Adv. Mater. Res. 278 (2011) 405-410.

[21] A. Devaux, E. Georges, P. Héritier, Properties of new C\&W superalloys for high temperature disk applications, Superalloy 718 and Derivatives. (2010) 222-235.

[22] P. Wright, Machinability of Metals, Pergamon Press, Encyclopedia of Materials Science and Engineering. 4 (1986).

[23] A. Thakur, S. Gangopadhyay, State-of-the-art in surface integrity in machining of nickel-based super alloys, Int. J. Mach. Tools Manuf. 100 (2016) 25-54.

[24] D. Ulutan, T. Ozel, Machining induced surface integrity in titanium and nickel alloys: A review, Int. J. Mach. Tools Manuf. 51 (2011) 250-280. 
[25] R. Arunachalam, M.A. Mannan, Machinability of nickel-based high temperature alloys, Mach. Sci. Technol. 4 (2000) 127-168.

[26] E. Ezugwu, J. Bonney, Y. Yamane, An overview of the machinability of aeroengine alloys, J. Mater. Process. Technol. 134 (2003) 233-253.

[27] J.P. Davim, Machining: Fundamentals and Recent Advances, Springer Science \& Business Media, 2008.

[28] M.C. Shaw, Metal Cutting Principles, Oxford university press New York, 2005.

[29] S. Veldhuis, G. Dosbaeva, A. Elfizy, G. Fox-Rabinovich, T. Wagg, Investigations of white layer formation during machining of powder metallurgical Ni-based ME 16 superalloy, J. Mater. Eng. Perform. 19 (2010) 1031-1036.

[30] J. Lorentzon, N. Järvstråt, B. Josefson, Modelling chip formation of alloy 718, J. Mater. Process. Technol. 209 (2009) 4645-4653.

[31] G. Dong, H. Zhaopeng, H. Rongdi, C. Yanli, J. Muguthu, Study of cutting deformation in machining nickel-based alloy Inconel 718, Int. J. Mach. Tools Manuf. 51 (2011) 520-527.

[32] N. Abukhshim, P. Mativenga, M. Sheikh, Heat generation and temperature prediction in metal cutting: A review and implications for high speed machining, Int. J. Mach. Tools Manuf. 46 (2006) 782-800.

[33] F. Klocke, D. Welling, J. Dieckmann, D. Veselovac, R. Perez, Developments in wire-EDM for the manufacturing of fir tree slots in turbine discs made of Inconel 718, Key Eng. Mater. 504 (2012) 1177-1182.

[34] P. Vogtel, F. Klocke, D. Lung, High performance machining of profiled slots in nickel-based-superalloys, Procedia CIRP. 14 (2014) 54-59.

[35] S. Kalpakjian, S.R. Schmid, K.V. Sekar, Manufacturing Engineering and Technology, Prentice Hall, 2014.

[36] N.M. Abbas, D.G. Solomon, M.F. Bahari, A review on current research trends in electrical discharge machining (EDM), Int. J. Mach. Tools Manuf. 47 (2007) 12141228 .

[37] J. Kruth, L. Stevens, L. Froyen, B. Lauwers, Study of the white layer of a surface machined by die-sinking electro-discharge machining, CIRP Annals-Manuf. Technol. 44 (1995) 169-172. 
[38] T.R. Newton, S.N. Melkote, T.R. Watkins, R.M. Trejo, L. Reister, Investigation of the effect of process parameters on the formation and characteristics of recast layer in wire-EDM of Inconel 718, Mater. Sci. Eng. A. 513 (2009) 208-215.

[39] H. Lee, T.Y. Tai, Relationship between EDM parameters and surface crack formation, J. Mater. Process. Technol. 142 (2003) 676-683.

[40] B. Ekmekci, Residual stresses and white layer in electric discharge machining (EDM), Appl. Surf. Sci. 253 (2007) 9234-9240.

[41] Z. Chen, J. Moverare, R.L. Peng, S. Johansson, Surface integrity and fatigue performance of Inconel 718 in wire electrical discharge machining, Procedia CIRP. 45 (2016) 307-310.

[42] S. Jeelani, M. Collins, Effect of electric discharge machining on the fatigue life of Inconel 718, Int. J. Fatigue. 10 (1988) 121-125.

[43] T. Tai, S. Lu, Improving the fatigue life of electro-discharge-machined SDK11 tool steel via the suppression of surface cracks, Int. J. Fatigue. 31 (2009) 433-438.

[44] D. Welling, Results of surface integrity and fatigue study of wire-EDM compared to broaching and grinding for demanding jet engine components made of Inconel 718, Procedia CIRP. 13 (2014) 339-344.

[45] J. Champaigne, Shot peening overview, Metal Improvement Company. (2001).

[46] L.L. Shaw, J. Tian, A.L. Ortiz, K. Dai, J.C. Villegas, P.K. Liaw, R. Ren, D.L. Klarstrom, A direct comparison in the fatigue resistance enhanced by surface severe plastic deformation and shot peening in a C-2000 superalloy, Mater. Sci. Eng. A. 527 (2010) 986-994.

[47] J. Lindemann, C. Buque, F. Appel, Effect of shot peening on fatigue performance of a lamellar titanium aluminide alloy, Acta Mater. 54 (2006) 1155-1164.

[48] L. Wagner, Mechanical surface treatments on titanium, aluminum and magnesium alloys, Mater. Sci. Eng. A. 263 (1999) 210-216.

[49] D. Los Rios, Improving the fatigue crack resistance of Waspaloy by shot peening, Fatigue Fract. Eng. Mater. Struct. 21 (1998) 1513-1524.

[50] P. Peyre, X. Scherpereel, L. Berthe, C. Carboni, R. Fabbro, G. Beranger, C. Lemaitre, Surface modifications induced in 316L steel by laser peening and shotpeening. Influence on pitting corrosion resistance, Mater. Sci. Eng. A. 280 (2000) 294-302. 
[51] Y. Al-Obaid, The effect of shot peening on stress corrosion cracking behaviour of 2205-duplex stainless steel, Eng. Fract. Mech. 51 (1995) 19-25.

[52] M. Field, J. Kahles, The surface integrity of machined-and ground high-strength steels, DMIC Report. 210 (1964) 54-77.

[53] M. Field, J.F. Kahles, W.P. Koster, Surface finish and surface integrity, ASM Handbook. 16 (1989) 19-36.

[54] D. Novovic, R.C. Dewes, D.K. Aspinwall, W. Voice, P. Bowen, The effect of machined topography and integrity on fatigue life, Int. J. Mach. Tools Manuf. 44 (2004) 125-134.

[55] Z. Chen, J.J. Moverare, R.L. Peng, S. Johansson, D. Gustafsson, On the conjoint influence of broaching and heat treatment on bending fatigue behavior of Inconel 718, Mater. Sci. Eng. A. 671 (2016) 158-169.

[56] J. Zhou, V. Bushlya, J. Stahl, An investigation of surface damage in the high speed turning of Inconel 718 with use of whisker reinforced ceramic tools, J. Mater. Process. Technol. 212 (2012) 372-384.

[57] A. Sadat, M. Reddy, Surface integrity of inconel-718 nickel-base superalloy using controlled and natural contact length tools. part I: Lubricated, Exp. Mech. 32 (1992) 282-288.

[58] A. Sadat, M. Reddy, Surface integrity of inconel-718 nickel-base superalloy using controlled and natural contact length tools. Part II: Unlubricated, Exp. Mech. 33 (1993) 343-348.

[59] R. Pawade, S.S. Joshi, P. Brahmankar, Effect of machining parameters and cutting edge geometry on surface integrity of high-speed turned Inconel 718, Int. J. Mach. Tools Manuf. 48 (2008) 15-28.

[60] C. Che-Haron, A. Jawaid, The effect of machining on surface integrity of titanium alloy Ti-6\%Al-4\%V, J. Mater. Process. Technol. 166 (2005) 188-192.

[61] R. M'Saoubi, D. Axinte, C. Herbert, M. Hardy, P. Salmon, Surface integrity of nickel-based alloys subjected to severe plastic deformation by abusive drilling, CIRP Annals-Manuf. Technol. 63 (2014) 61-64.

[62] E. Ezugwu, Z. Wang, C. Okeke, Tool life and surface integrity when machining Inconel 718 with PVD-and CVD-coated tools, Tribol. Trans. 42 (1999) 353-360.

[63] J. Stead, Micro-metallography and its practical applications, Journal of Western Scottish Iron and Steel Institute. 19 (1912) 169-204. 
[64] J. Barry, G. Byrne, TEM study on the surface white layer in two turned hardened steels, Mater. Sci. Eng. A. 325 (2002) 356-364.

[65] V. Bushlya, J. Zhou, F. Lenrick, P. Avdovic, J. Ståhl, Characterization of white layer generated when turning aged Inconel 718, Procedia Eng. 19 (2011) 60-66.

[66] Y. Guo, D.W. Schwach, An experimental investigation of white layer on rolling contact fatigue using acoustic emission technique, Int. J. Fatigue. 27 (2005) 10511061.

[67] D.W. Schwach, Y. Guo, A fundamental study on the impact of surface integrity by hard turning on rolling contact fatigue, Int. J. Fatigue. 28 (2006) 1838-1844.

[68] Y. Xu, L. Fang, Q. Cen, J. Zhu, Nano structure and transformation mechanism of white layer for AISI1045 steel during impact wear, Wear. 258 (2005) 537-544.

[69] S. Bosheh, P. Mativenga, White layer formation in hard turning of $\mathrm{H} 13$ tool steel at high cutting speeds using CBN tooling, Int. J. Mach. Tools Manuf. 46 (2006) 225233.

[70] F. Klocke, D. Welling, A. Klink, D. Veselovac, T. Nöthe, R. Perez, Evaluation of advanced wire-EDM capabilities for the manufacture of fir tree slots in Inconel 718, Procedia CIRP. 14 (2014) 430-435.

[71] H. Zhang, S. Ohsaki, S. Mitao, M. Ohnuma, K. Hono, Microstructural investigation of white etching layer on pearlite steel rail, Mater. Sci. Eng. A. 421 (2006) 191-199.

[72] J. Takahashi, K. Kawakami, M. Ueda, Atom probe tomography analysis of the white etching layer in a rail track surface, Acta Mater. 58 (2010) 3602-3612.

[73] J. Kundrák, Z. Gácsi, K. Gyáni, V. Bana, G. Tomolya, X-ray diffraction investigation of white layer development in hard-turned surfaces, Int. J. Adv. Manuf. Technol. 62 (2012) 457-469.

[74] P. Withers, H. Bhadeshia, Residual stress. Part 1-measurement techniques, Mater. Sci. Technol. 17 (2001) 355-365.

[75] P. Withers, H. Bhadeshia, Residual stress. Part 2-Nature and origins, Mater. Sci. Technol. 17 (2001) 366-375.

[76] E. Brinksmeier, J. Cammett, W. König, P. Leskovar, J. Peters, H. Tönshoff, Residual stresses-measurement and causes in machining processes, CIRP AnnalsManuf. Technol. 31 (1982) 491-510. 
[77] A. Sharman, J. Hughes, K. Ridgway, An analysis of the residual stresses generated in Inconel $718^{\mathrm{TM}}$ when turning, J. Mater. Process. Technol. 173 (2006) 359-367.

[78] C. Schlauer, R.L. Peng, M. Odén, Residual stresses in a nickel-based superalloy introduced by turning, Mater. Sci. Forum. 404 (2002) 173-178.

[79] B. Subhas, R. Bhat, K. Ramachandra, H. Balakrishna, Dimensional instability studies in machining of Inconel 718 nickel based superalloy as applied to aerogas turbine components, J. Eng. Gas Turb. Power. 122 (2000) 55-61.

[80] B. Subhas, R. Bhat, K. Ramachandra, H. Balakrishna, Simultaneous optimization of machining parameters for dimensional instability control in aero gas turbine components made of Inconel 718 alloy, J. Manuf. Sci. Eng. 122 (2000) 586-590.

[81] M.B. Bever, D.L. Holt, A.L. Titchener, The stored energy of cold work, Prog. Mater. Sci. 17 (1973) 5-177.

[82] Z. Chen, R.L. Peng, P. Avdovic, J. Zhou, J. Moverare, F. Karlsson, S. Johansson, Effect of thermal exposure on microstructure and nano-hardness of broached Inconel 718, MATEC Web of Conference.14 (2014) 08002.

[83] S. Suresh, Fatigue of Materials, Cambridge university press, 1998.

[84] A. Hunsche, P. Neumann, Quantitative measurement of persistent slip band profiles and crack initiation, Acta Metall. 34 (1986) 207-217.

[85] M. Bao-Tong, C. Laird, Overview of fatigue behavior in copper single crystalsI. Surface morphology and stage I crack initiation sites for tests at constant strain amplitude, Acta Metall. 37 (1989) 325-336.

[86] Z. Zhang, Z. Wang, Y. Hu, Fatigue crack initiation and fracture behavior of a copper bicrystal with a perpendicular grain boundary, Mater. Sci. Eng. A. 269 (1999) 136-141.

[87] P. Lukáš, L. Kunz, Cyclic slip localisation and fatigue crack initiation in fcc single crystals, Mater. Sci. Eng. A. 314 (2001) 75-80.

[88] P. Lukáš, L. Kunz, Role of persistent slip bands in fatigue, Philos. Mag. 84 (2004) 317-330.

[89] S. Nishijima, K. Kanazawa, Stepwise SN curve and fish-eye failure in gigacycle fatigue, Fatigue Fract. Eng. Mater. Struct. 22 (1999) 601-608. 
[90] Y. Murakam, T. Nomoto, T. Ueda, Factors influencing the mechanism of superlong fatigue failure in steels, Fatigue Fract. Eng. Mater. Struct. 22 (1999) 581590.

[91] Q. Wang, J. Berard, S. Rathery, C. Bathias, Technical note High-cycle fatigue crack initiation and propagation behaviour of high-strength sprin steel wires, Fatigue Fract. Eng. Mater. Struct. 22 (1999) 673-677.

[92] K.S. Chan, P. Jones, Q. Wang, Fatigue crack growth and fracture paths in sand cast B319 and A356 aluminum alloys, Mater. Sci. Eng. A. 341 (2003) 18-34.

[93] F. Alexandre, S. Deyber, A. Pineau, Modelling the optimum grain size on the low cycle fatigue life of a $\mathrm{Ni}$ based superalloy in the presence of two possible crack initiation sites, Scr. Mater. 50 (2004) 25-30.

[94] L. Kunz, P. Lukáš, R. Konečná, High-cycle fatigue of Ni-base superalloy Inconel 713LC, Int. J. Fatigue. 32 (2010) 908-913.

[95] S. Jha, M. Caton, J. Larsen, A new paradigm of fatigue variability behavior and implications for life prediction, Mater. Sci. Eng. A. 468 (2007) 23-32.

[96] D. Texier, A.C. Gómez, S. Pierret, J. Franchet, T.M. Pollock, P. Villechaise, J. Cormier, Microstructural features controlling the variability in low-cycle fatigue properties of alloy Inconel 718DA at intermediate temperature, Metall. Mater. Trans. A. 47 (2016) 1096-1109.

[97] J. Hyzak, I. Bernstein, The effect of defects on the fatigue crack initiation process in two P/M superalloys: Part I. Fatigue origins, Metall. Trans. A. 13 (1982) 33-43.

[98] Q. Wang, D. Apelian, D. Lados, Fatigue behavior of A356-T6 aluminum cast alloys. Part I. Effect of casting defects, J. Light Met. 1 (2001) 73-84.

[99] C. Sonsino, J. Ziese, Fatigue strength and applications of cast aluminium alloys with different degrees of porosity, Int. J. Fatigue. 15 (1993) 75-84.

[100] X. Zhu, J. Jones, J. Allison, Effect of frequency, environment, and temperature on fatigue behavior of E319 cast aluminum alloy: stress-controlled fatigue life response, Metall. Mater. Trans. A. 39 (2008) 2681-2688.

[101] V. Norman, P. Skoglund, D. Leidermark, J. Moverare, The effect of superimposed high-cycle fatigue on thermo-mechanical fatigue in cast iron, Int. J. Fatigue. 88 (2016) 121-131. 
[102] Q. Wang, C. Bathias, N. Kawagoishi, Q. Chen, Effect of inclusion on subsurface crack initiation and gigacycle fatigue strength, Int. J. Fatigue. 24 (2002) $1269-1274$.

[103] C. Szczepanski, S. Jha, J. Larsen, J. Jones, Microstructural influences on veryhigh-cycle fatigue-crack initiation in Ti-6246, Metall. Mater. Trans. A. 39 (2008) 2841-2851.

[104] M. Oja, K.R. Chandran, R. Tryon, Orientation imaging microscopy of fatigue crack formation in Waspaloy: crystallographic conditions for crack nucleation, Int. J. Fatigue. 32 (2010) 551-556.

[105] K. Le Biavant, S. Pommier, C. Prioul, Local texture and fatigue crack initiation in a Ti-6Al-4V titanium alloy, Fatigue Fract. Eng. Mater. Struct. 25 (2002) 527-545.

[106] D.L. Davidson, R. Tryon, M. Oja, R. Matthews, K.R. Chandran, Fatigue crack initiation in Waspaloy at $20^{\circ} \mathrm{C}$, Metall. Mater. Trans. A. 38 (2007) 2214-2225.

[107] D. Arola, C. Williams, Estimating the fatigue stress concentration factor of machined surfaces, Int. J. Fatigue. 24 (2002) 923-930.

[108] S. Ås, B. Skallerud, B. Tveiten, B. Holme, Fatigue life prediction of machined components using finite element analysis of surface topography, Int. J. Fatigue. 27 (2005) 1590-1596.

[109] L. Li, Y. Guo, X. Wei, W. Li, Surface integrity characteristics in wire-EDM of Inconel 718 at different discharge energy, Procedia CIRP. 6 (2013) 220-225.

[110] P. Bleys, J. Kruth, B. Lauwers, B. Schacht, V. Balasubramanian, L. Froyen, J. Van Humbeeck, Surface and sub-surface quality of steel after EDM, Adv. Eng. Mater. 8 (2006) 15-25.

[111] D. Aspinwall, S. Soo, A. Berrisford, G. Walder, Workpiece surface roughness and integrity after WEDM of Ti-6Al-4V and Inconel 718 using minimum damage generator technology, CIRP Annals-Manuf. Technol. 57 (2008) 187-190.

[112] J.J. Moverare, G. Leijon, H. Brodin, F. Palmert, Effect of SO 2 and water vapour on the low-cycle fatigue properties of nickel-base superalloys at elevated temperature, Mater. Sci. Eng. A. 564 (2013) 107-115.

[113] T. Connolley, P. Reed, M. Starink, Short crack initiation and growth at $600^{\circ} \mathrm{C}$ in notched specimens of Inconel718, Mater. Sci. Eng. A. 340 (2003) 139-154.

[114] S. Rokhlin, J. Kim, H. Nagy, B. Zoofan, Effect of pitting corrosion on fatigue crack initiation and fatigue life, Eng. Fract. Mech. 62 (1999) 425-444. 
[115] P.C. Paris, M.P. Gomez, W.E. Anderson, A rational analytic theory of fatigue, Trend Eng. 13 (1961) 9-14.

[116] P. Paris, F. Erdogan, A critical analysis of crack propagation laws, J. Basic Eng. 85 (1963) 528-533.

[117] B. Leis, A. Hopper, J. Ahmad, D. Broek, M. Kanninen, Critical review of the fatigue growth of short cracks, Eng. Fract. Mech. 23 (1986) 883-898.

[118] A. Pineau, S.D. Antolovich, High temperature fatigue of nickel-base superalloys-a review with special emphasis on deformation modes and oxidation, Eng. Failure Anal. 16 (2009) 2668-2697.

[119] D. Fournier, A. Pineau, Low cycle fatigue behavior of Inconel 718 at $298 \mathrm{~K}$ and 823 K, Metall. Trans. A. 8 (1977) 1095-1105.

[120] M. Kassner, Y. Kosaka, J. Hall, Low-cycle dwell-time fatigue in Ti-6242, Metall. Mater. Trans. A. 30 (1999) 2383-2389.

[121] D. Gustafsson, E. Lundström, High temperature fatigue crack growth behaviour of Inconel 718 under hold time and overload conditions, Int. J. Fatigue. 48 (2013) 178-186.

[122] J. Saarimäki, J. Moverare, R. Eriksson, S. Johansson, Influence of overloads on dwell time fatigue crack growth in Inconel 718, Mater. Sci. Eng. A. 612 (2014) 398405.

[123] D. Coates, Kikuchi-like reflection patterns obtained with the scanning electron microscope, Philos. Mag. 16 (1967) 1179-1184.

[124] G. Booker, A. Shaw, M. Whelan, P. Hirsch, Some comments on the interpretation of the 'Kikuchi-like reflection patterns' observed by scanning electron microscopy, Philos. Mag. 16 (1967) 1185-1191.

[125] J.J. Moverare, S. Johansson, R.C. Reed, Deformation and damage mechanisms during thermal-mechanical fatigue of a single-crystal superalloy, Acta Mater. 57 (2009) 2266-2276.

[126] I. Gutierrez-Urrutia, S. Zaefferer, D. Raabe, Electron channeling contrast imaging of twins and dislocations in twinning-induced plasticity steels under controlled diffraction conditions in a scanning electron microscope, Scr. Mater. 61 (2009) 737-740. 
[127] I. Gutierrez-Urrutia, D. Raabe, Dislocation and twin substructure evolution during strain hardening of an Fe-22wt.\% Mn-0.6 wt.\% C TWIP steel observed by electron channeling contrast imaging, Acta Mater. 59 (2011) 6449-6462.

[128] J. Talonen, H. Hänninen, Formation of shear bands and strain-induced martensite during plastic deformation of metastable austenitic stainless steels, Acta Mater. 55 (2007) 6108-6118.

[129] A.J. Schwartz, M. Kumar, B.L. Adams, D.P. Field, Electron Backscatter Diffraction in Materials Science, Springer, 2009.

[130] A. Wilkinson, D. Dingley, Quantitative deformation studies using electron back scatter patterns, Acta Metall. Mater. 39 (1991) 3047-3055.

[131] R. Ørsund, J. Hjelen, E. Nes, Local lattice curvature and deformation heterogeneities in heavily deformed aluminium, Scr. Metall. 23 (1989) 1193-1197.

[132] J.M. Zhou, V. Bushlya, R.L. Peng, J.E. Stahl, Identification of subsurface deformation in machining of Inconel 718, Appl. Mech. Mater. 117 (2012) 1681-1688.

[133] J.I. Goldstein, D.E. Newbury, P. Echlin, D.C. Joy, C. Fiori, E. Lifshin, Scanning Electron Microscopy and X-Ray Microanalysis. A Text for Biologists, Materials Scientists, and Geologists, Plenum Publishing Corporation, 1981.

[134] S. Schlegel, S. Hopkins, E. Young, J. Cole, T. Lillo, M. Frary, Precipitate redistribution during creep of alloy 617, Metall. Mater. Trans. A. 40 (2009) 28122823.

[135] D. Newey, M. Wilkins, H. Pollock, An ultra-low-load penetration hardness tester, J. Phys. E: Sci. Instrum. 15 (1982) 119-122.

[136] J. Pethicai, R. Hutchings, W. Oliver, Hardness measurement at penetration depths as small as $20 \mathrm{~nm}$, Philos. Mag. A. 48 (1983) 593-606.

[137] R. Saha, W.D. Nix, Effects of the substrate on the determination of thin film mechanical properties by nanoindentation, Acta Mater. 50 (2002) 23-38.

[138] G. Pharr, W. Oliver, Measurement of thin film mechanical properties using nanoindentation, MRS Bull. 17 (1992) 28-33.

[139] D. Li, Y. Chung, M. Wong, W.D. Sproul, Nano-indentation studies of ultrahigh strength carbon nitride thin films, J. Appl. Phys. 74 (1993) 219-223. 
[140] W.C. Oliver, G.M. Pharr, An improved technique for determining hardness and elastic modulus using load and displacement sensing indentation experiments, J. Mater. Res. 7 (1992) 1564-1583.

[141] I.C. Noyan, J.B. Cohen, Residual stress-measurement by diffraction and interpretation, (1986).

[142] T. Zhai, Y. Xu, J. Martin, A. Wilkinson, G. Briggs, A self-aligning four-point bend testing rig and sample geometry effect in four-point bend fatigue, Int. J. Fatigue. 21 (1999) 889-894 


\section{Papers}

The articles associated with this thesis have been removed for copyright reasons. For more details about these see:

http://urn.kb.se/resolve? urn:nbn:se:liu:diva-134124 